Portland State University

PDXScholar

Dissertations and Theses

Dissertations and Theses

Summer 1-1-2012

\title{
Designing New Drugs to Treat Cardiac Arrhythmia
}

Yanping Ye

Portland State University

Follow this and additional works at: https://pdxscholar.library.pdx.edu/open_access_etds

Part of the Cardiovascular Diseases Commons, and the Medical Biophysics Commons Let us know how access to this document benefits you.

\section{Recommended Citation}

Ye, Yanping, "Designing New Drugs to Treat Cardiac Arrhythmia" (2012). Dissertations and Theses. Paper 638.

https://doi.org/10.15760/etd.638

This Dissertation is brought to you for free and open access. It has been accepted for inclusion in Dissertations and Theses by an authorized administrator of PDXScholar. Please contact us if we can make this document more accessible: pdxscholar@pdx.edu. 
Designing New Drugs to Treat Cardiac Arrhythmia

\title{
by
}

Yanping Ye

A dissertation submitted in partial fulfillment of the requirements for the degree of

\author{
Doctor of Philosophy \\ in \\ Applied Physics
}

\author{
Dissertation Committee: \\ Jonathan Abramson, Chair \\ David Peyton \\ Drake Mitchell \\ Rajendra Solanki \\ Robert Strongin
}

\author{
Portland State University \\ (C)2012
}




\begin{abstract}
Heart failure resulting from different forms of cardiomyopathy is defined as the inability of the heart to pump sufficient blood to meet the body's metabolic demands. It is a major disease burden worldwide and the statistics show that $50 \%$ of the people who have the heart failure will eventually die from sudden cardiac death (SCD) associated with an arrhythmia. The central cause of disability and SCD is because of ventricular arrhythmias.

Genetic mutations and acquired modifications to RyR2, the calcium release channel from sarcoplasmic reticulum, can increase the pathologic SR $\mathrm{Ca}^{2+}$ leak during diastole, which leads to defects in SR calcium handling and causes ventricular arrhythmias. The mechanism of RyR2 dysfunction includes abnormal phosphorylation, disrupted interaction with regulatory proteins and ions, or altered RyR2 domain interactions. Many pharmacological strategies have shown promising prospects to modulate the RyR2 as a therapy for treating cardiac arrhythmias.
\end{abstract}

Here, we are trying to establish a novel approach to designing new drugs to treat heart failure and cardiac arrhythmias. Previously, we demonstrated that all pharmacological inhibitors of RyR channels are electron donors while all activators of RyR channels are electron acceptors. This was the first demonstration that an exchange of electrons was a common molecular mechanism involved in modifying the function of the RyR. Moreover, we found that there is a strong correlation between the strength of the electron donor/acceptor, and its potency as a channel inhibitor/activator, which could serve as a basis and direction for developing new drugs targeting the RyR. 
In this study, two new potent RyR inhibitors, 4-methoxy-3-methyl phenol (4-MmC) and the 1,3 dioxole derivative of K201, were synthesized which are derivatives of the known RyR modulators, 4-chloro-3-methyl phenol (4-CmC) and K201. The ability of K201, 1,3 dioxole derivative of $\mathrm{K} 201$ and 4-MmC to inhibit the cardiac calcium channel is examined and compared at the single channel level. All of these compounds inhibited the channel activity at low micromolar concentrations or sub-micromolar concentrations. 


\section{ACKNOWLEDGEMENTS}

Throughout my years of study in Portland, I have met many nice and wonderful people. It would not have been possible to write this doctoral thesis without the help and support of those people.

My first sincere gratitude must go to my advisor Prof. Abramson. He patiently provided me the vision, encouragement and advice necessary for me to proceed through my research projects and complete my dissertation. His wisdom and passion for science has been an inspiration.

Special thanks to my committee, Prof. Drake Mitchell, Prof. David Peyton, Prof. Raj Solanki, Prof. Robert Strongin for their interest in my research, their support and insightful comments. Sincere thanks to Prof Pavel Smejtek, for all his encouragement and help. I also would like to thank my labmates, Tom Dornan, Laura Owen, Robert Klipp and all of the people who have passed through the Abramson's lab. Their friendship and assistance has meant to me a lot. I think we had a good time.

Last but not the least, I would like to thank my parents, Bingren Ye and Jufen Han, for their unconditional support and love. I owe them everything and wish I could show them how much I love them and appreciate them. 
ABSTRACT $\cdots \cdots \cdots \cdots \cdots \cdots \cdots \cdots \cdots \cdots \cdots \cdots \cdots \cdots \cdots \cdots \cdots \cdots \cdots \cdots \cdots \cdots \cdots \cdots \cdots \bullet$

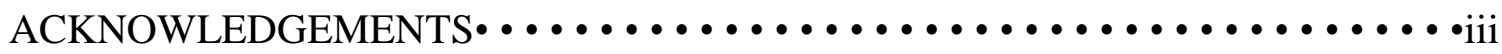

LIST OF TABLES $\cdots \ldots \ldots \ldots \ldots \ldots \ldots \ldots \ldots \ldots \ldots \ldots \ldots \ldots \ldots \ldots \ldots \ldots \ldots$. $\ldots \ldots \ldots$ vii

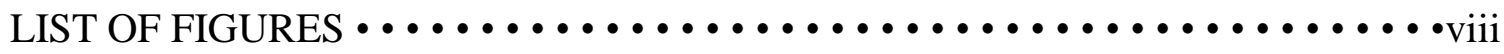

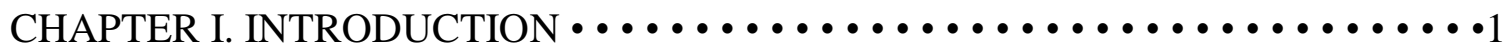

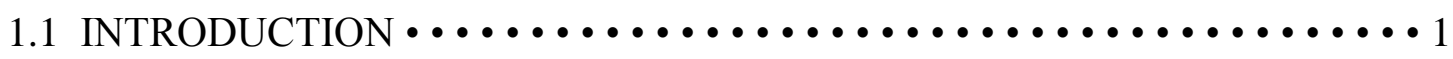

$1.2 \operatorname{MUSCLE} \bullet \ldots \ldots \ldots \ldots \ldots \ldots \ldots \ldots \ldots \ldots \ldots \ldots \ldots \ldots \ldots \ldots \ldots \ldots \ldots \ldots$

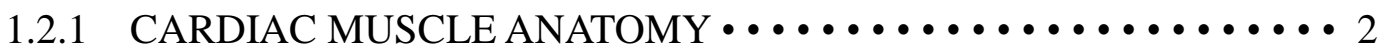

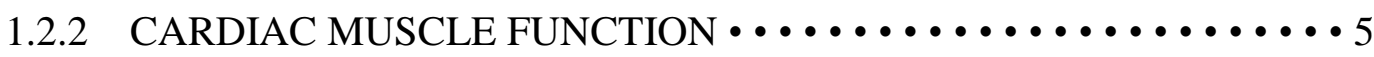

1.3 FUNCTION AND REGULATION OF CARDIAC CALCIUM RELEASE

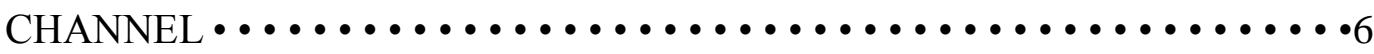

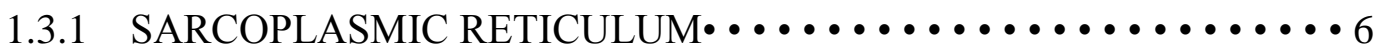

1.3.2 STRUCTURE AND FUNCTION OF RYANODINE RECEPTOR $\bullet \cdots \bullet 8$

1.3.3 REGULATION OF CALCIUM RELEASE CHANNEL•••••••••11

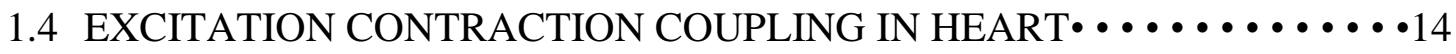

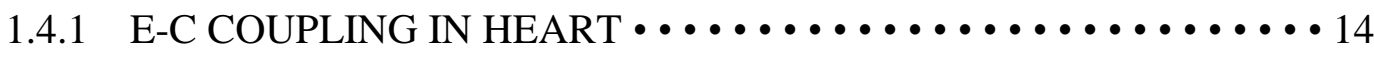

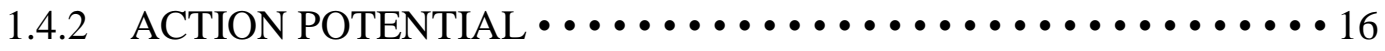

1.5 RYANODINE RECEPTOR-MEDIATED ARRHYTHMIAS AND HEART

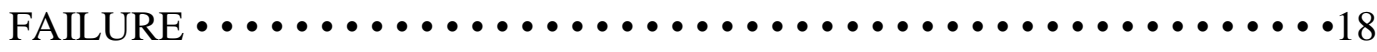


1.5.1 MOLECULAR MECHANISMS OF RYANODINE RECEPTOR TYPE-2

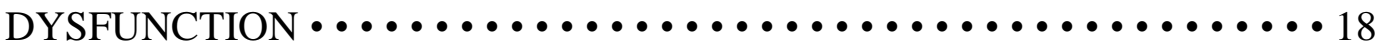
1.5.2 CATECHOLAMINERGIC POLYMORPHIC VENTRICULAR

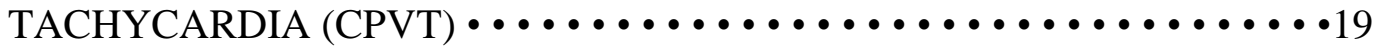

1.6 THE HYPOTHESIS UNDERLYING THE DESIGN OF NEW DRUGS TO MODIFYING RYANODINE RECEPTOR・•••••••••••••••••• 20

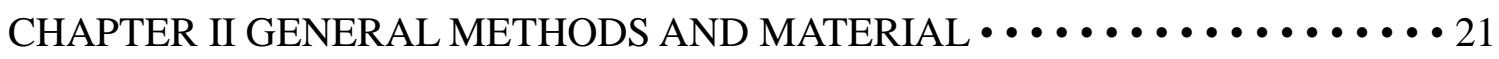

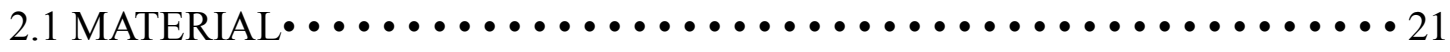

2.1.1 PREPARATION OF CARDIAC SARCOPLASMIC RETICULUM $・ ・ 21$

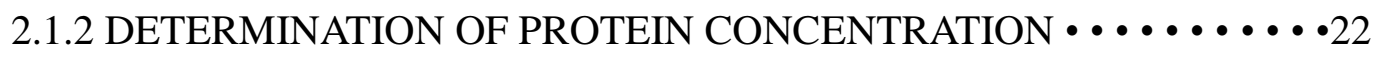

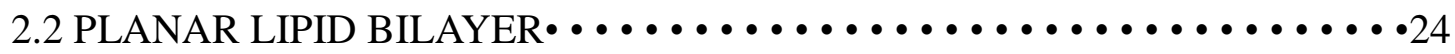

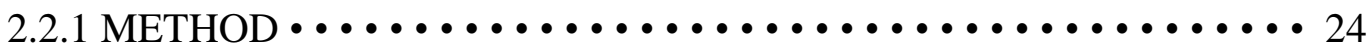

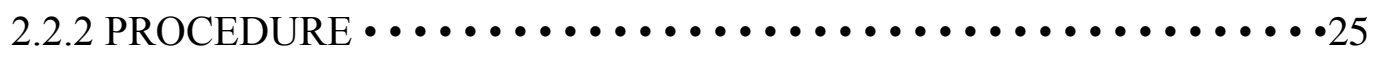

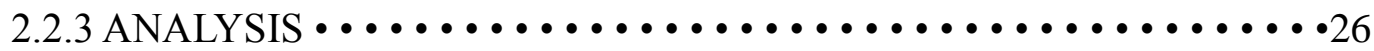

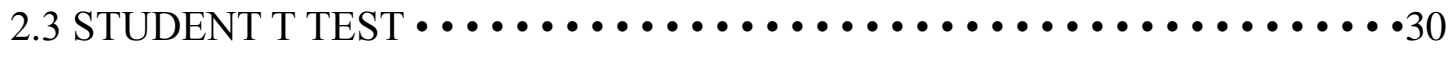

2.4 DYE PHOTOSENSITIZED ELECTRON DONOR/ ACCEPTOR TEST $・ \cdots ・ 31$

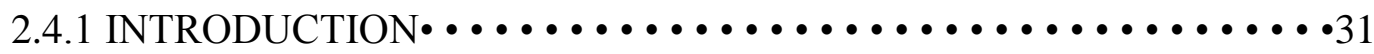


2.5 INTRODUCTION TO ANTIARRYTHMIC DRUGS $\cdot \cdots \cdots \cdots \cdots \cdots \cdot \cdots$

2.5.1 K201 AND THE DIOXOLE DERIVATIVE OF K201 $・ \cdots \cdots \cdots \cdots \cdots 36$

2.5.2 4-METHOXY-3-METHYLPHENOL $\cdots \cdots \cdots \cdots \cdots \cdots \cdots \cdots 38$

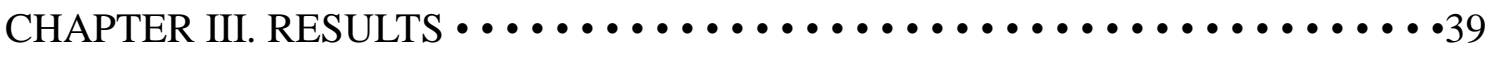

3.1 K201 INHIBITS CARDIAC CALCIUM RELEASE CHANNEL (RYR2) • ••40

3.2 THE DIOXOLE DERIVATIVE OF K201 IS A MORE POTENT INHIBITOR OF RYR2 THAN K201 $\ldots \ldots \ldots \ldots \ldots \ldots \ldots \ldots \ldots \ldots \ldots \ldots$

3.3 4-METHOXY-3-METHYL PHENOL INHIBITS RYR2 AT LOWER SALT

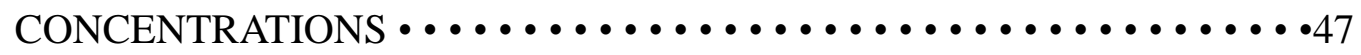

3.4 THREE DRUGS DECREASE THE CHANNEL OPEN PROBABILITIES AND OPEN TIMES BUT DON'T AFFECT THE CHANNEL CLOSED DURATION•

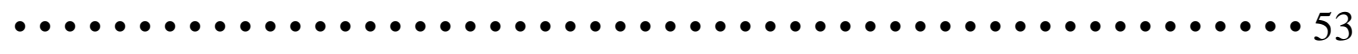

CHAPTER IV. DISCUSSION $\cdot \cdots \cdots \cdots \cdots \cdots \cdots \cdots \cdots \cdots \cdots \cdot \ldots 1$

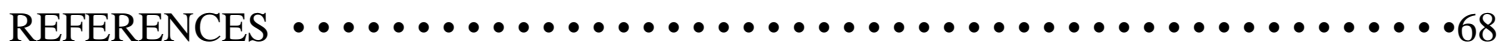




\section{LIST OF TABLES}

1.1 Modulators of the SR RyR channel $\ldots \ldots \ldots \ldots \ldots \ldots \ldots \ldots \ldots \ldots \ldots \ldots$ 


\section{LIST OF FIGURES}

1.2 Transmission electron micrograph of ventricular walls $\bullet \ldots \ldots \ldots \ldots \ldots \ldots \ldots \ldots$

1.3 Diagrammatic representation of the sarcoplasmic reticulum showing its regular arrangement with respect to the myofibrils $\bullet \ldots \ldots \ldots \ldots \ldots \ldots \ldots \ldots \ldots \ldots \ldots \ldots$

1.4 3D reconstruction of the ryanodine receptor $\ldots \ldots \ldots \ldots \ldots \ldots \ldots$

1.5 Schematic of cardiomyocyte excitation-conctraction coupling $\cdots \cdots \cdots \cdots \cdots \cdots$

1.6 Cardiac action potential $\ldots \ldots \ldots \ldots \ldots \ldots \ldots \ldots \ldots \ldots \ldots$

2.1 Schematic representation of the BLM setup in the Abramson's lab $\bullet \cdots \cdots \cdots 29$

2.2 Initial and reduced structure of Methylene Blue $\bullet . . . . . . . . . . . .33$

2.3 Scheme showing the protocol for measuring the electron acceptor/ donor properties of

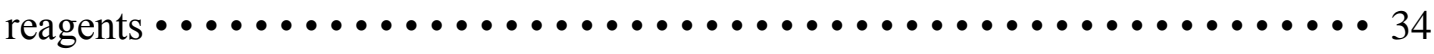

2.4 Chemical structure of $\mathrm{K} 201 \cdot \ldots \ldots \ldots \ldots \ldots \ldots \ldots \ldots$

2.5 Chemical structure of the dioxole derivative of K201 $\ldots \ldots \ldots \ldots \ldots \ldots$

2.6 Chemical structure of 4-Chloro-m-Cresol and 4-Methoxy-3-Methylphenol $\bullet \cdots \cdots 38$

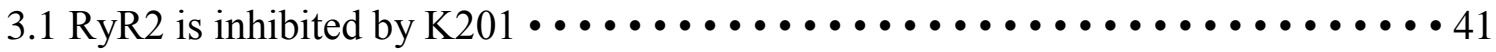

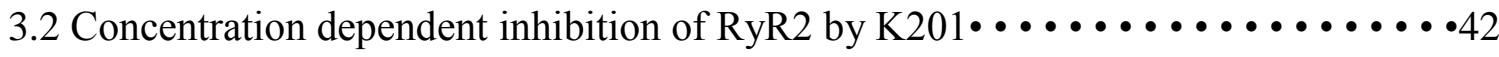

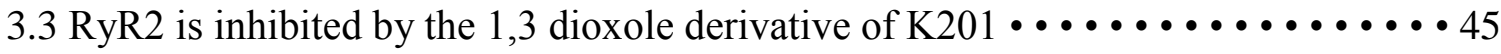

3.4 Concentration dependent inhibition of RyR2 by the 1,3 dioxole derivative of K201 46

3.5 RyR2 inhibited by the 4-Methoxy-3-Methyl-phenol at relatively low salt

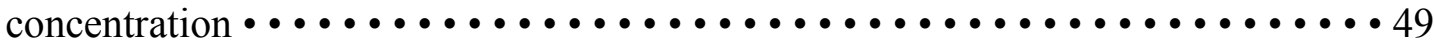

3.6 4-Methoxy-3-Methyl-phenol is a potent inhibitor of the RyR2 at low salt

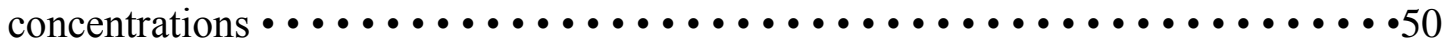


3.7 4-Methoxy-3-Methyl-phenol activates the cardiac CRC at high salt concentrations $\bullet 51$

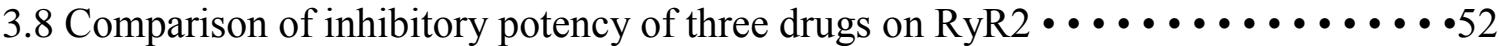

3.9 K201 has no significant effect on channel closed time $(\tau) \cdot \ldots \ldots \ldots \ldots \ldots \ldots$

3.10 K201 decreases channel open time $\left(\tau_{\mathrm{o}}\right) \cdot \ldots \ldots \ldots \ldots \ldots \ldots \ldots \ldots$

3.11 1,3 dioxole derivative of K201 has no significant effect on channel closed time $\left(\tau_{\mathrm{c}}\right)$

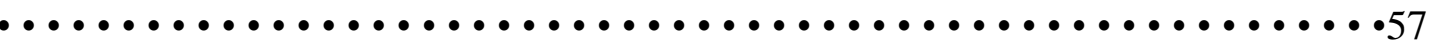

$3.121,3$ dioxole derivative of $\mathrm{K} 201$ decreases channel open time $\left(\tau_{\mathrm{o}}\right) \cdot \cdots \cdots \cdots$

3.13 4-Methoxy-3-Methyl -phenol has no significant effect on channel closed time $\left(\tau_{\mathrm{c}}\right) \bullet$

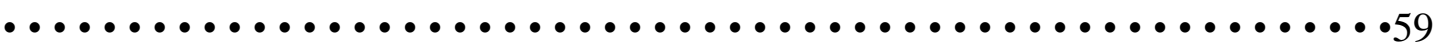

3.14 4-Methoxy-3-Methyl -phenol decreases channel opens $\left(\tau_{\mathrm{o}}\right) \bullet \cdots \cdots \cdots \cdots$ 


\section{CHAPTER I}

\section{INTRODUCTION}

\subsection{INTRODUCTION}

Heart failure resulting from different forms of cardiomyopathies is characterized by the inability of the heart to pump sufficient blood to meet the body's metabolic demands[1]. Heart failure is a major disease burden worldwide and statistics show that $50 \%$ of the people who have heart failure will die from sudden cardiac death (SCD) associated with an arrhythmia.

Genetic mutations and acquired modifications on cardiac ryanodine receptor (RyR2) can increase the pathologic sarcoplasmic reticulum $(\mathrm{SR}) \mathrm{Ca}^{2+}$ leak during diastole, which leads to defects in SR calcium handling and causes ventricular arrhythmias $[2,3]$. The mechanisms of RyR2 dysfunction include abnormal phosphorylation, disrupted interaction with regulatory proteins and ions, or altered RyR2 domain interaction[4]. One pharmacological strategy that has shown promise is to modulate the RyR2 as a therapy for treating cardiac arrhythmias.

In this study, the molecular mechanism of how three drugs, K201, the dioxole derivative of K201 and 4-methoxy-3-methyl-phenol, modify the activity of sheep heart RyR2 will be investigated. 


\subsection{MUSCLE}

Muscle is a contractile tissue that is composed of bundles of fibers, which constitute from a third to a half of the bulk of vertebrates. It can produce motion for some useful functions, such as heat generation, circulation and digestion. The sizes and shapes of muscles vary, depending on the different types of tasks that muscles must perform. The longer a muscle, the more it can shorten and the higher its peak velocity of shortening; In contrast, the thicker a muscle, the more force it can develop.

According to its morphology and different modes of contraction, muscle can be classified as skeletal, cardiac and smooth muscle. Skeletal and cardiac are together known as striated muscles because of the striped appearance of their fibers, in alternating bands of light and dark when observed under a microscope. Although skeletal and cardiac muscle have similar structure, they are controlled by different mechanisms. Skeletal muscle which is consciously controlled by the nervous system is known as voluntary muscle, whereas cardiac muscle is activated through involuntary pathways. Smooth muscles, consisting of enlongated fusiform cells, are also examples of involuntary muscle. They contract relatively slowly and have the ability to maintain contraction for a long period of time.

\subsubsection{CARDIAC MUSCLE ANATOMY}

Cardiac muscle is a type of involuntary striated muscle found in the walls of the heart. It resembles skeletal muscle in that both muscle types contain actin and myosin filaments, 
and they contact through the sliding filament mechanism. Whereas skeletal muscle fibers are long, fibrous and are functionally separated from one another, cardiac muscle cells are short, branched and interconnected. Cardiac muscle also has a well developed Ttubule system. T-tubules in cardiac muscle appear to be larger, broader and run along the Z Discs. Figure 1.1 shows a longitudinally arrayed, striped pattern of cardiac myofibrils, which comprise the I bands, A bands, and Z bands. Each longitudinal unit of myofibrils is called a sarcomere.

Unlike the other muscle types, cardiac muscles have intercalated discs (IDs) that connect the individual myocytes together. The IDs are perpendicular to the direction of muscle fibres. They consist of three different types of cell-cell junctions, one of which is called a gap junction. Gap junctions are responsible for electrochemical and metabolic coupling, which allows an action potential to easily and quickly spread to all cells of the heart. 


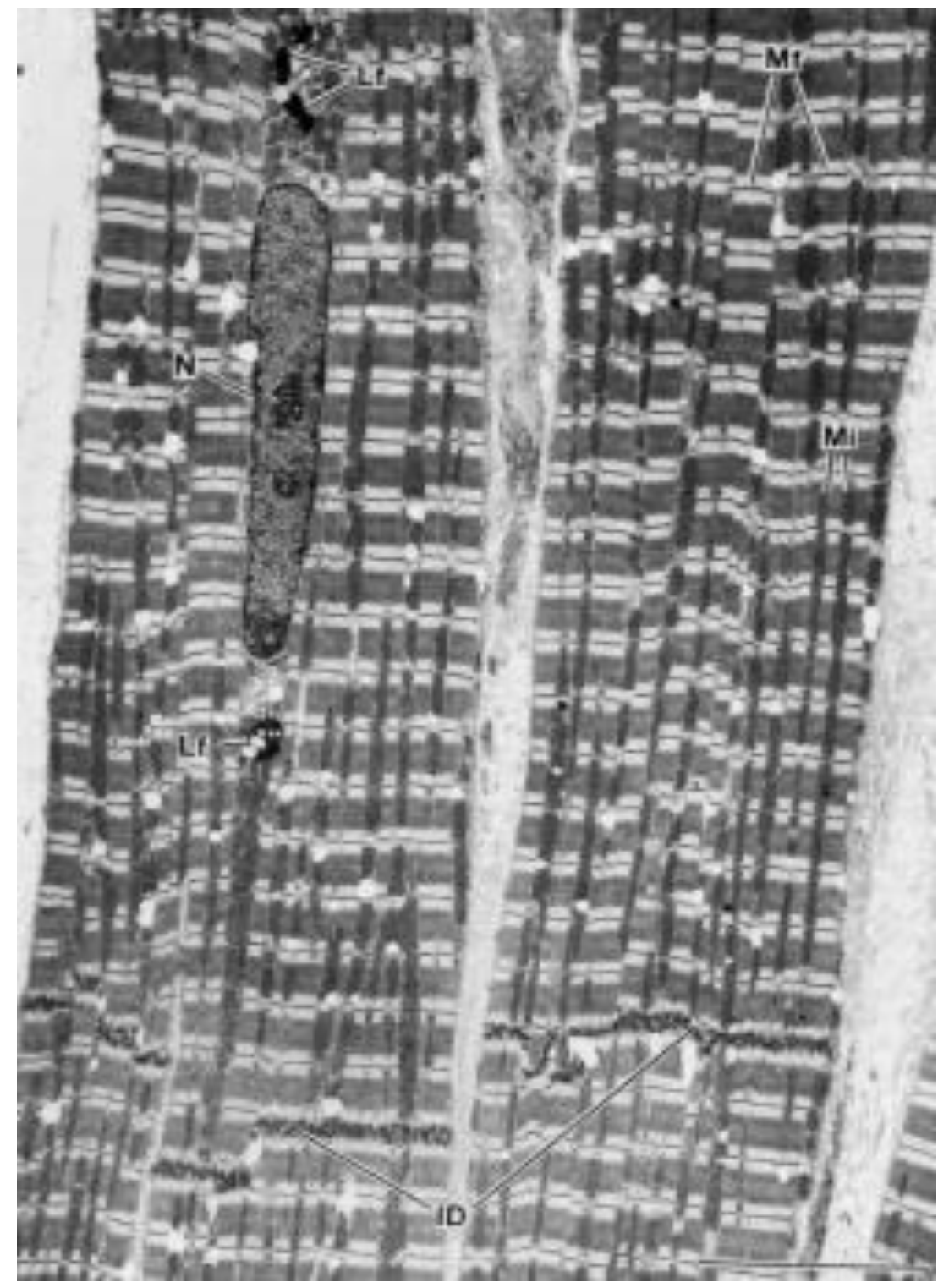

Figure 1.1 Transmission electron micrograph of ventricular walls [5]. 


\subsubsection{CARDIAC MUSCLE FUNCTION}

The cardiac myocyte has a negative membrane potential at rest and is responsible for contraction of the atria and ventricles of the heart. Unlike skeletal muscle, the cardiac muscle cells communicate with each other directly by passing the action potential (AP) to their neighbors through synaptic gap-junctions. In addition, cardiac muscle is able to produce action potentials automatically through groups of specialized cells called pacemaker cells which are located on the atria. 


\subsection{FUNCTION AND REgUlation OF THE CARDIAC CALCIUM RELEASE CHANNEL}

\subsubsection{SARCOPLASMIC RETICULUM}

The sarcoplasmic reticulum (SR) is a convoluted structure lying on the surface of the myofibrils and bounded by a membrane, which is specialized for the cyclical uptake, storage, and release of calcium ions. It plays an important role in muscular contraction and relaxation by regulating cytosolic $\mathrm{Ca}^{2+}$ concentration. As the calcium is taken up into the SR, the cytosolic $\mathrm{Ca}^{2+}$ concentration is lowered and muscle relaxes. Releasing the

$\mathrm{Ca}^{2+}$ from the SR into the cytosol initiates muscle contraction. Two key proteins are of significant importance in regulating the cytosolic $\mathrm{Ca}^{2+}$ concentration - the ryanodine receptor (RyR) and the calcium pump.

Structurally, the SR can be divided into two portions, the terminal cisternae and the longitudinal cisternae (Fig 1.2). The terminal cisternae are closely apposed to the Ttubule and contain a large amount of calcium binding proteins. Vesicles derived from terminal cisternae also known as heavy SR, contain a large density of calcium release channels. The longitudinal cisternae are mainly composed of calcium pumps and rarely contain calcium binding proteins. SR vesicles derived from the longitudinal SR are referred to as light SR (LSR). The SR is connected to T-tubule by feet-like projections in the region of the terminal cisternae. This region, known as junctional SR, is concerned with transmission of the impulse from the T-tubule to the SR causing calcium release. The transverse tubule system and terminal cisternae together is called the triad. 


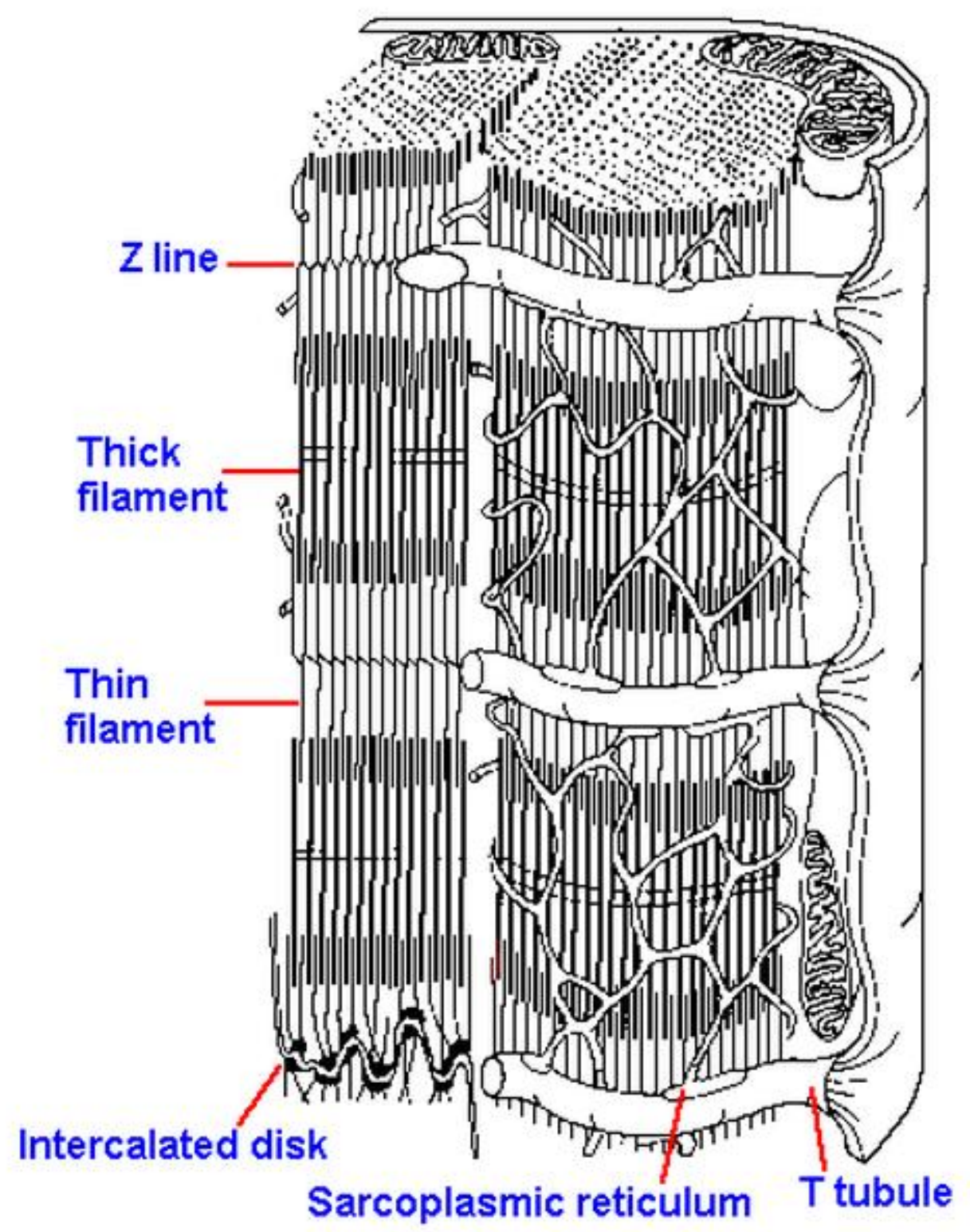

Figure 1.2. Diagrammatic representation of the sacoplasmic reticulum(SR) showing its regular arrangement with respect to the myofibrils [6]. 


\subsubsection{SRUCTURE AND FUNCTION OF THE RYANODINE RECEPTOR}

The calcium release channel is a ligand-gated channel also known as the ryanodine receptor (RyR), the function of which is to release $\mathrm{Ca}^{2+}$ ions rapidly from its lumen into the cytosol and trigger the contractile mechanism of the muscle fiber. There are three subtypes of RyR isoforms, the labeling of which is based on the chronological order of their initial purification. Those isoforms are isolated from a variety of tissues and exhibit different pharmacological properties. Subtypes of 1 and 3 of RyR isoforms have been shown to appear in early stages of skeletal muscle development. However, in adult animals, RyR1 is predominantly found only in all skeletal muscles while RyR3 display a differential distribution, having been observed in smooth muscle and brain. In cardiac myocytes, RyR2 has been shown to be expressed.

Fig 1.3 shows a 3D structure of the RyR. The size is determined to be $28 * 28 * 12 \mathrm{~nm}$. It is a homotetramer, consisting of four individual subunits and each individual protein has an approximately molecular weight of $564 \mathrm{kDa}$ [7]. The microscopic image reveals RyR1 has four- fold symmetry with a large cytoplasmic domain and a relatively small transmembrane region. The central cavity has a diameter of approximately $2 \mathrm{~nm}$ and is connected to four peripheral channels that extend from partway across the membrane to the cytoplasmic end. The rest of the protein lying between the T-tubule and SR membrane is known as the foot region, which links the Ryanodine receptor to the DHPR in the T-tubule membrane. It provides a direct physical interaction between the voltage sensing protein in the T-tubule membrane and the SR calcium release channel. 


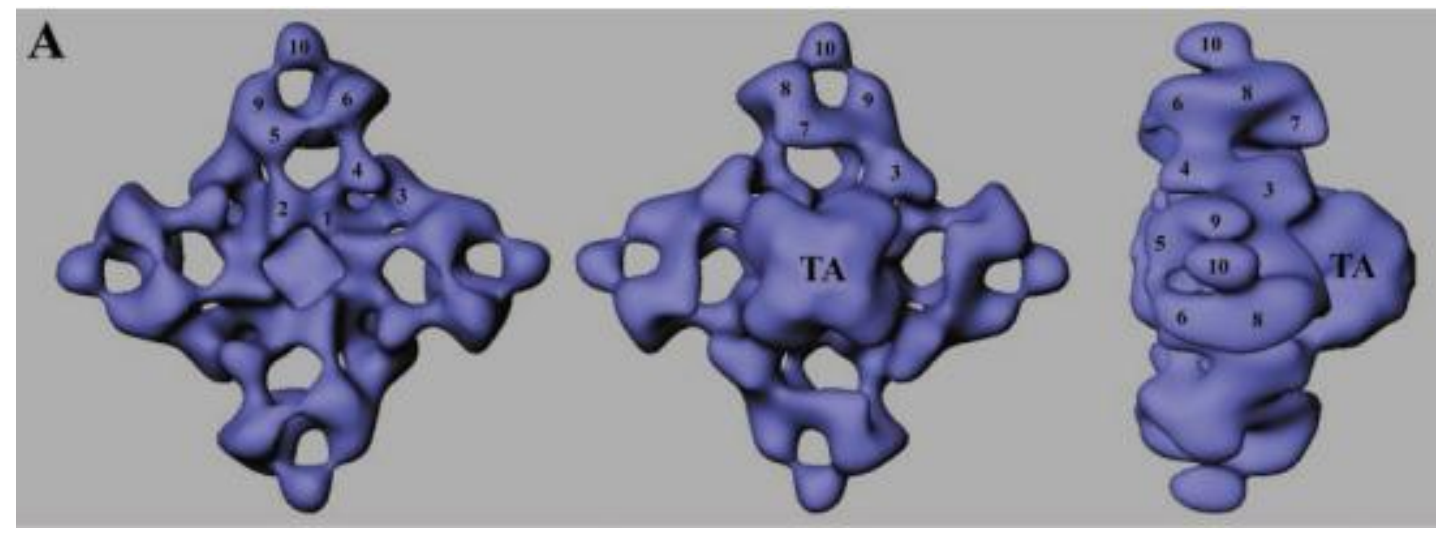

Figure 1.3 3D reconstruction of the ryanodine receptor [8]

It is shown in three different views. View from cytoplasm, view from SR lumen and side view. The transmembrane region of RyR is shown in a side view with the SR luminal face down.

Three major proteins with high affinity for calcium are involved in regulation of muscle contraction.

\section{Calmodulin}

Calmodulin $(\mathrm{CaM})$ is a binding protein with a molecular weight of $16.8 \mathrm{KD}$ and contains four calcium binding domains [9]. Each domain contains 12 amino acid residues forming a "pocket" for a $\mathrm{Ca}^{2+}$ ion. CaM binds directly to the RyR and decreases channel opening at concentrations at around $2 \mu \mathrm{M}$. As a calcium sensor and signal transducer, CaM binds 
to and activates many proteins that are unable to bind calcium themselves. It can bind up to four calcium ions, and can undergo post-translational modifications, such as phosphorylation, acetylation, and methylation.

\section{Triadin}

Triadin is a transmembrane protein with molecular weight of $95 \mathrm{KD}$. It was discovered in 1990 [10] and was originally proposed to play a critical role in E-C coupling. However, many researchers later showed that triadin only indirectly influences E-C coupling. Triadin is associated with the RyR, calsequestrin and junctin to form a macromolecular calcium signaling complex in the junctional SR [9]. This association facilitates cross-talk between calsequestrin and the RyR. Junctin was later discovered [11] and it is believed to have a comparable function to triadin, due to its similar structure and ability to bind both calsequestrin and the RyR.

\section{Calsequestrin}

Calsequestrin, the second most abundant protein constituent of the SR, is a low affinity high capacity calcium-binding protein. It functions as a calcium buffer in the SR lumen. It readily releases $\mathrm{Ca}^{2+}$ when the calcium release channel in the SR opens.

\section{FKBP12 / FKBP12.6}

FKBP, also known as FK506 binding protein, is considered an integral part of the functional $\mathrm{Ca}^{2+}$ release channel. It belongs to the family of immunophilins and is a 
receptor for the immunosuppressive drugs FK-506 and rapamycin. It is believed that dissociation of FKBP12 / FKBP12.6 from the RyR1/RyR2 of SR increases the channel activity and the sensitivity of the channel to agonists such as $\mathrm{Ca}^{2+}$ and caffeine, and decreases the sensitivity to blockage by $\mathrm{Mg}^{2+}$. Rebinding of FKBP 12 restores these channel characteristics. A related protein, FKBP 12.6, is found in cardiac muscle, which modified the channel activity in a similar way.

\subsubsection{REGULATION OF CALCIUM RELEASE CHANNEL}

Calcium release channel (CRC) channel activity is regulated by a wide variety of endogenous molecules. Physiological ligand activators of the RyR include the dihydropyridine receptor (the voltage-sensor), $\mathrm{Ca}^{2+}$ at micromolar levels, and millimolar concentrations of ATP. Inhibitors include $\mathrm{Ca}^{2+}$ and $\mathrm{Mg}^{2+}$ at millimolar concentrations. Table 1.1 lists some of the modulators of the CRC.

$\mathrm{Ca}^{2+}, \mathrm{Mg}^{2+}$ and ATP are three key regulators of the channel. $\mathrm{Ca}^{2+}$ is thought to be the physiological channel activator because other ligands either cannot activate the channel in its absence or they require $\mathrm{Ca}^{2+}$ for maximum effect. Ryanodine binding assays, SR $\mathrm{Ca}^{2+}$ flux measurements and single channel recordings have shown that cytosolic $\mathrm{Ca}^{2+}$ has a biphasic effect on skeletal muscle RyR channel activity. The threshold concentration for channel activity is around $100 \mathrm{nM}$, while maximum activity is observed in the range of 10-100 $\mu \mathrm{M}$. Millimolar concentrations of $\mathrm{Ca}^{2+}$ inhibit the channel. The biphasic effect of $\mathrm{Ca}^{2+}$ on channel activity suggests that RyR1 contains high-affinity $\mathrm{Ca}^{2+}$-binding sites that stimulate the channel and inhibitory low-affinity binding sites. 
Table 1.1 Modulators of the SR RyR Channel

\begin{tabular}{|l|l|}
\hline ACTIVATORS & INHIBITORS \\
\hline $\mathrm{Ca}^{2+}(\mu \mathrm{M})$ & $\mathrm{Ca}^{2+}(>1 \mathrm{mM}), \mathrm{Mg}^{2+}(\mathrm{mM})$ \\
\hline Ryanodine $(100 \mathrm{nM}-10 \mu \mathrm{M})$ & Ryanodine $(100-300 \mu \mathrm{M})$ \\
\hline Quinones, Porphyrins & Ruthenium red $(0.1-5 \mu \mathrm{M})$ \\
\hline Doxorubicin(a quinone) & Tetracaine, Procaine \\
\hline Caffeine & Verapamil \\
\hline Pelargonidine & Polyunsaturated fatty acids \\
\hline Cu ${ }^{2+} /$ cysteine & 7-diethylamino-3-(4- \\
& maleimidolphenyl)-4-methylcoumarin \\
& $(\mathrm{CPM})$ \\
\hline Rose Bengal & Calmodulin \\
\hline GSSG & Lactate \\
\hline 4-CmC & K201 and its dioxole derivative \\
\hline Sulfhydryl oxidizing agents & Thiol reducing agents \\
\hline
\end{tabular}

$\mathrm{Mg}^{2+}$ is a potent CRC inhibitor and inhibits RyR in a dose dependent manner, with millimolar concentrations resulting in complete inactivation. It has been suggested that $\mathrm{Mg}^{2+}$ exerts its inhibitory effects by competing with $\mathrm{Ca}^{2+}$ for the high-affinity $\mathrm{Ca}^{2+}$ 
stimulatory sites and by binding to the low-affinity inactivation sites with an affinity comparable to $\mathrm{Ca}^{2+}$.

The adenine nucleotides ATP, ADP, AMP and cyclic-AMP, as well as adenine, are activators of RyR channel. It has been suggested that ATP increases the sensitivity of the channel to $\mathrm{Ca}^{2+}$ and decrease its sensitivity to $\mathrm{Ca}^{2+}$ inactivation.

The CRC from SR also can be regulated by altering its redox status. RyR is rich in thiol groups. The oxidation / reduction of those thiol groups by thiol reagents can activate / inhibit the CRC. Conditions that favor channel opening, such as making the redox potential of the RyR more negative. The RyR favors the oxidation of thiols, whereas conditions that close down the channel have the opposite effect. However, most channel modulators are non thiol reagents. Previous research in our lab showed that most of the non-thiol channel activators acts as electron acceptors, and channel inhibitors act as electron donors in free radical reactions [12]. Non-thiol channel regulators can shift the thiol-disulfide balance within $\mathrm{CRC}$ by transiently exchanging electrons with the $\mathrm{Ca}^{2+}$ release protein. 


\subsection{EXCITATION-CONTRACTION COUPLING IN HEART}

\subsubsection{E-C COUPLING IN HEART}

Fig 1.4 shows the key cellular components involved in EC coupling and calcium movement. Unlike skeletal muscle cell, there is no directly physical interaction between the dihydropyridine receptor (DHPR) (also known as the L-type $\mathrm{Ca}^{2+}$ channel) and RyR2 during EC coupling. When an action potential is initiated, the myocyte depolarizes and extracellular $\mathrm{Ca}^{2+}$ enters the cell through the DHPR. This inward $\mathrm{Ca}^{2+}$ current acts as an amplifier and in turn activates the RyR2 channels to release $\mathrm{Ca}^{2+}$ from the SR, which triggers contraction. This process is called "calcium induced calcium release" (CICR). It has been reported that the opening of a single DHPR channel triggers calcium release from 4-6 RyR2 channels [13]. Muscle relaxation is followed by the closure of RyR2 and rapid removal of cytosolic calcium, by reuptake of $\mathrm{Ca}^{2+}$ into the SR through the SERCA2 protein, and by efflux of $\mathrm{Ca}^{2+}$ out of cell by the $\mathrm{Na}^{+} / \mathrm{Ca}^{2+}$ exchange protein (NCX). 


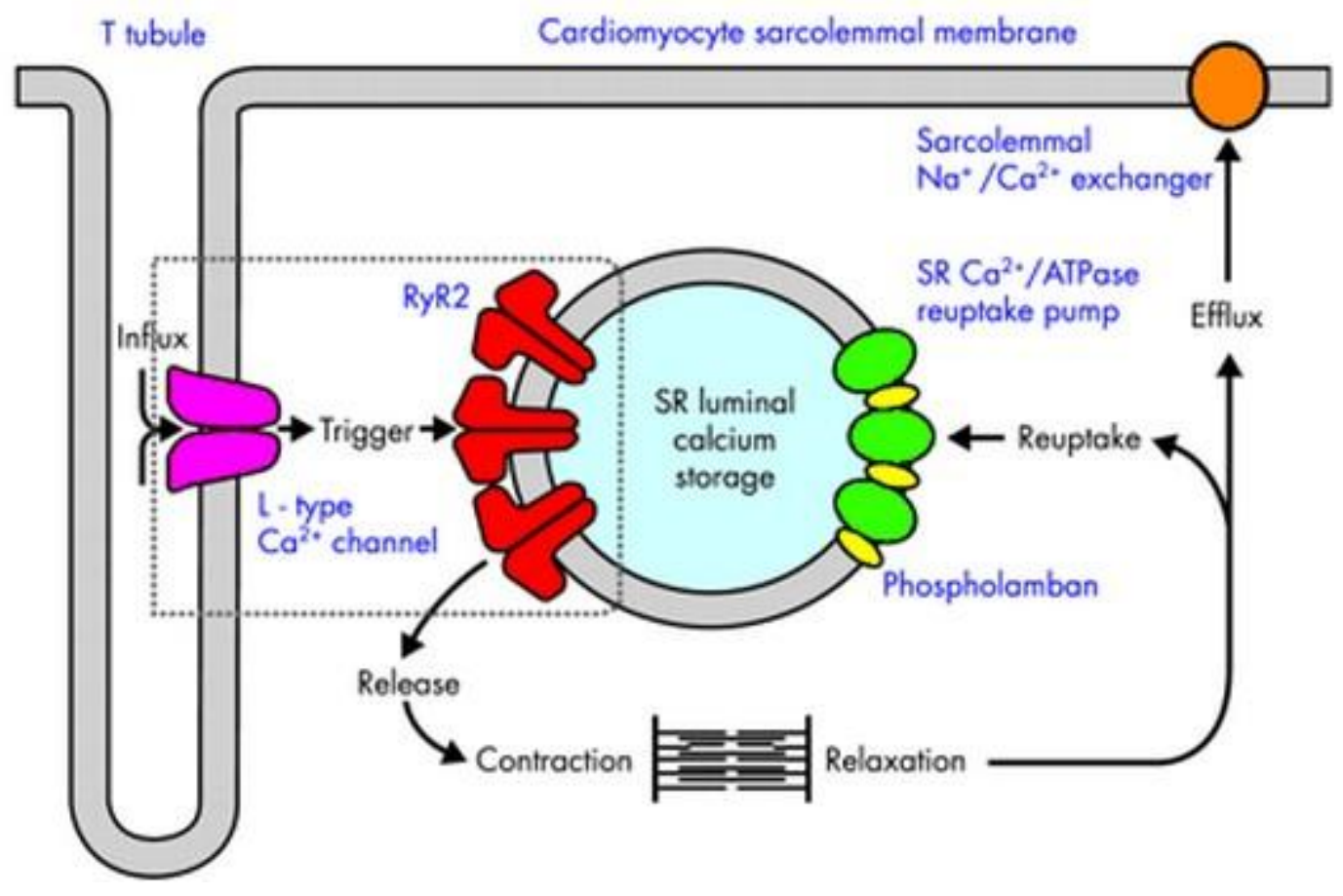

Fig 1.4 Schemetic of cardiomyocyte excitation- contraction coupling. Major components of EC coupling within a myocyte are shown [14]. 


\subsubsection{ACTION POTENTIAL}

The excitation and contraction coupling process in cardiac myocytes starts with the action potential. There are two types of cardiac action potentials in heart, fast response action potentials and slow response action potentials. The fast response action potentials, also called non-pacemaker action potentials, can be found throughout the heart except for the pacemaker cells. The duration of this action potential is around $200 \mathrm{~ms}$ to $400 \mathrm{~ms}$ depending on different animal species.

Fig 1.5 shows the time course of a normal action potential. Before the cell is stimulated by the electrical signal, the cardiac myocytes are at a resting membrane potential, which is $-80 \mathrm{mV}$. As cells are stimulated, an inward small flux of $\mathrm{Ca}^{2+}$ and $\mathrm{Na}^{+}$through gap junction occurs and the membrane potential is increased slightly to reach a threshold. This increase in the membrane potential opens the fast $\mathrm{Na}^{+}$channels and causes a large influx of $\mathrm{Na}^{+}$into the cell, which results in a rapidly depolarization of the cell membrane. After the rapid depolarization, there is a long lasting phase to the action potential, during which the potassium leaves the cell through the slow delayed rectifier potassium channels and the calcium enters the cell through L-type calcium channels. The deflection at the beginning of this stage was caused by the outward $\mathrm{K}^{+}$current. As the potential slowly

comes down, the $\mathrm{L}$ - type $\mathrm{Ca}^{2+}$ channels close while the slow delayed rectifier $\mathrm{K}^{+}$channels are still open. This leads to a negative change in membrane potential and tends to open the outward rapid delayed rectifier $\mathrm{K}^{+}$channel. This net outward current causes the cell to repolarize to its resting potential. 


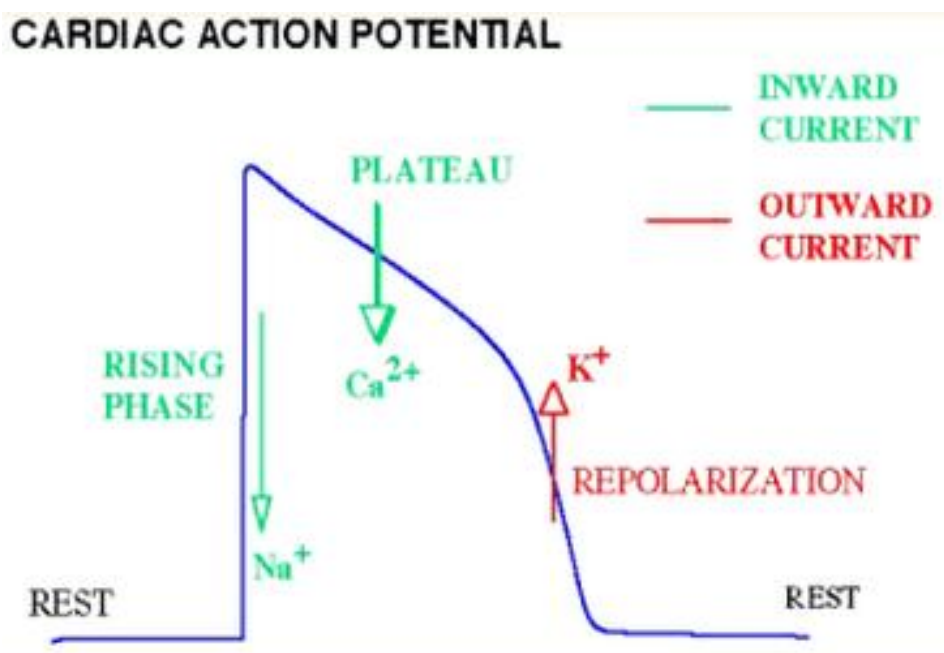

Fig 1.5. Cardiac Action Potential [15] 


\subsection{RYANODINE RECEPTOR-MEDIATED ARRHYTHMIAS AND HEART \\ FAILURE}

Heart failure is a major disease which is responsible for $>300,000$ deaths per year in the US alone. $50 \%$ of the people who have the heart disease will eventually die from sudden cardiac death (SCD) associated with an arrhythmia. The cardiac disturbance is usually caused by alterations in the expression or function of several key proteins involved in regulating and maintaining ionic homeostasis [16]. Ryanodine receptors are one of the most important groups of such proteins. Rapid release of $\mathrm{Ca}^{2+}$ by the sarcoplasmic reticulum membrane in the heart induced by $\mathrm{Ca}^{2+}$ via the $\mathrm{RyR} 2$ receptor is a critical step in cardiac contractility. The malfunction of RyR2 can result in diastolic $\mathrm{Ca}^{2+}$ leak and cause a delayed after depolarization (DAD), which is a major feather of arrhythmias in HF [17].

\subsubsection{MOLECULAR MECHANISMS OF RYANODINE RECEPTOR TYPE-2 DYSFUNCTION}

The molecular mechanism of ryanodine receptor dysfunction is highly controversial. There are two main hypothesizes. The hyperphosphorylation hypothesis suggests that the hyperphosphorylation of RyR2 is caused by the loss of two phosphatases (PP1 and PP2A) and results in the debinding of the modulator protein FKBP12.6 from the RyR2 complex, which destabilizes the channel [18]. Several research groups have shown that the treatment with $\beta$ blocker reversed PKA-mediated hyperphosphorylation of RyR2 [19, 20]. restored cardiac function and reduced the rate of mortality in patients with $\operatorname{HF}$ [21, 22]. 
Several RyR2 phosphorylation sites have been found that are related to HF. The S2809 residue has been shown to be hyperphosphorylated during $\mathrm{HF}$ in myocardium from in a removed human heart [18]. An alternative hypothesis suggests that the gating of channel is regulated by 'unzipping' of interacting domains within the RyR2 molecule [23].

\subsubsection{CATECHOLAMINERGIC POLYMORPHIC VENTRICULAR TACHYCARDIA (CPVT)}

CPVT is an inherited disorder associated with mutations in either the RyR2 (CPVT1) or a SR luminal protein, calsequestrin (CVPT2). Patients with CPVT have structurally normal hearts and present with ventricular arrhythmias at physical or emotional stress. 69 point mutations were found in the RyR2 gene in 253 (out of 915) patients screened for CPVT1and this number is growing [4]. On the other hand, only a few patients have been identified with CPVT2 symptoms which have mutations in the calsequestrin. 


\subsection{THE HYPOTHESIS UNDERLYING THE DESIGN OF NEW DRUGS TO MODIFY RYANODINE RECEPTOR FUNCTION}

In this study, we are trying to establish a novel approach to design new drugs to treat dysfunctions associate with RyR. It has been shown that there are a large number of chemically diverse compounds which can either activate or inhibit the $\mathrm{SR} \mathrm{Ca}^{2+}$ release channel. The common characteristic of most channel activators is their ability to act as electron acceptors, and common to the channel inhibitors is their electron donor characteristics. Moreover, we find that there is a strong correlation between the strength of the electron donor/acceptor, and its potency as a channel inhibitor/activator [12]. It occurred to us that this could serve as a basis and direction for developing new drugs targeting the RyR.

The redox activity of drugs and proteins that interact with the $\mathrm{Ca}^{2+}$ release channel is a key factor in modifying function of the SR. It is well established that thiol reducing agents inhibit RyR, while thiol oxidizing agents activate the release channel. Reduction of endogenous disulfides on the RyR1 inhibits the flux of $\mathrm{Ca}^{2+}$ across the SR [24], channel activity, and high affinity ryanodine binding [25]. The hypothesis that novel drugs with enhanced electron donor properties act as more potent inhibitors of RyR is consistent with the role of redox reactions in channel gating. 


\section{CHAPTER II}

\section{GENERAL METHODS AND MATERIALS}

\subsection{MATERIALS}

\subsubsection{PREPARATION OF CARDIAC SARCOPLASMIC RETICULUM}

Cardiac sarcoplasmic reticulum vesicles were isolated from sheep ventricles. The sheep heart was removed from host animal upon anesthetization and kept in the homogenization buffer containing $10 \mathrm{mM}$ imidazole, $3 \mathrm{mM} \mathrm{NaN}_{3}, 0.29 \mathrm{M}$ sucrose, $1 \mu \mathrm{g} / \mathrm{ml}$ leupeptin and a protease inhibitor tablet (sigma \# S8830) at pH6.9. The heart was bled and both the left and right atria were discarded. The remaining ventricles were cleaned by removing all the exterior and interior fat and connective tissue.

Upon preparation, $80 \mathrm{~g}$ of cardiac ventricles from a single sheep heart were minced and placed in $1 \mathrm{~L}$ homogenization buffer. The mixture was blended for 15 seconds at low speed and three times 15 seconds at high speed. The homogenate was poured into 6 Type19 tubes and then centrifuged at $9000 \mathrm{rpm}$ for 19 mins in a Beckman type-19 rotor. The supernatant was filtered through 4 layers of cheesecloth and centrifuged for 75 mins at $19000 \mathrm{rpm}$ in the Beckman type-19 rotor. The supernatant from this spin was carefully poured into a beaker and the brown pellet was resuspended in $\mathrm{KCl}$ buffer which contains $0.65 \mathrm{M} \mathrm{KCl}$ in homogenization buffer at $\mathrm{pH}$ 6.7. The mixture was distributed into two Ti60 tubes and incubated on ice for 30 mins. The incubated sample was centrifuged at 5000 rpm for 11 mins in Ti-60 rotor. The supernatant from this step was transferred to two 
other clean Ti-60 tubes and the pellet was discarded. The supernatant was spun at 50,000 rpm for 30 mins in Ti-60 rotor. The resulting supernatant was discarded and the pellets were carefully removed and placed in a glass homogenizer. The combined pellets were then homogenized in $5 \mathrm{ml} \mathrm{KCl}$ buffer using a $7 \mathrm{ml}$ manual glass homogenizer. The final sample was stored in liquid nitrogen in aliquots. This process yielded around $30 \mathrm{mgs}$ of SR from the original $80 \mathrm{~g}$ of ventricles.

\subsubsection{DETERMINATION OF PROTEIN CONCENTRATION}

The protein concentration of the SR prep was determined from ultraviolet absorbance at $230 \mathrm{~nm}, 260 \mathrm{~nm}, 280 \mathrm{~nm}$ wavelength according to the method of Kalckar (1947) [26].

Aromatic amino acids, particularly tyrosine and tryptophan absorb in the ultraviolet at $280 \mathrm{~nm}$. Since most proteins contain these two residues, their concentration can be successfully estimated by measuring the absorbance at $280 \mathrm{~nm}$ wavelength. The absorbance peak at $230 \mathrm{~nm}$ is produced by the backbone peptide bonds. This method uses absorption characteristics at $280 \mathrm{~nm}$ and $230 \mathrm{~nm}$ wavelength to calculate the protein concentration, while the peak at $260 \mathrm{~nm}$ wavelength is used as a correction factor to cancel the possibility of contamination by nucleic acid.

With absorbance measurements at these three wavelengths, the protein concentration can be calculated from follow simplified equations:

$(\mathrm{SR})_{\mathrm{mg} / \mathrm{ml}}=1.45\left(\mathrm{Abs}_{280}\right)-0.74\left(\mathrm{Abs}_{260}\right)$ 
$(\mathrm{SR})_{\mathrm{mg} / \mathrm{ml}}=185\left(\mathrm{Abs}_{230}\right)-74.8\left(\mathrm{Abs}_{260}\right)$

Three measurements are taken at each wavelength with increasing volumes of SR being added and the final protein concentration is calculated as a mean \pm standard deviation. 


\subsection{PLANAR LIPID BILAYER}

\subsubsection{METHOD}

Single-channel recording techniques with artificial bilayer membranes have been applied to various types of channel proteins in order to observe their physiological and pharmacological properties. It provides a method for observing the kinetic properties of individual ion channels.

The bilayers were usually formed using a modification of the film drainage method developed by Mueller [27]. Lipid in a hydrophobic solvent was smeared across a hole in a plastic septum to produce a thick lipid film separating two baths. The bilayer forms spontaneously from this thick film. After the formation of bilayer, ion channel proteins are added. The incorporation of ion channels into membranes occur spontaneously and this can be detected by conductance changes in the bilayer. For studying SR ion channels, the bilayers are produced across an aperture with a diameter of approximately $100 \mu \mathrm{m}$. The final concentration of SR vesicles is usually around $1-10 \mu \mathrm{g} / \mathrm{ml}$. The side of the bath to which vesicles are added is referred to as the cis side. Following fusion, this corresponds to the outside of the SR. The other side, trans, corresponds to the luminal side. There are several conditions that promote vesicle fusion: a gradient in osmotic strength across the membrane (cis high); cis $\left[\mathrm{Ca}^{2+}\right]$ at $\mu \mathrm{M}$ concentration; and vigorous stirring of the cis bath. 
This artificial membrane system, before incorporation of the $\mathrm{Ca}^{2+}$ release channel (CRC) is impermeable to both anions and cations. Cis and trans side are loaded with a buffer appropriate to the experiment and the bilayer is formed. Cesium methane sulfonate $\left(\mathrm{Cs}^{+} \mathrm{CH}_{3} \mathrm{O}_{3} \mathrm{~S}^{-}\right)$is commonly used as the principal salt in the bath solution, since $\mathrm{CH}_{3} \mathrm{O}_{3} \mathrm{~S}^{-}$ is unable to cross the membrane through any $\mathrm{SR}$ pore and $\mathrm{Cs}^{+}$is the only ion channel permeable charge carrier. This prevents current signals from other ion channels from interfering with CRC recordings.

When the SR fuses with a bilayer, ionic conductance, as well as open and close state, can be monitored by measuring the current through the membrane in response to an applied electrochemical gradient. This allows us to examine the response of channel to a variety of substances in the cytosolic and luminal baths and also changes in the composition of the bilayer itself.

\subsubsection{PROCEDURE}

Figure 2.1 A shows a overview of the bilayer lipid membrane (BLM) setup in Dr Abramson's lab. The amplifier and the signal generator (Warner BC-525A) is the center of the apparatus. $\mathrm{Ag} / \mathrm{AgCl}$ electrodes were inserted into a preamplifier to detect current. Salt bridge (4 $\mathrm{M} \mathrm{CsCl}$, agarose) provides an interface for the exchange of ions while preventing the introduction of silver into the bilayer solution. The amplified signal interfaced into an Axon Instruments Digidata 1322A digitizer was recorded by the ClampEx patch clamp chart recorder from the Axon Instruments pClamp 9.0 software package. The bilayer chamber consists of a cup with a 150 to $200 \mu \mathrm{m}$ hole of a thin 
walled region midheight and a base holder. The holder contains a subtracted column sufficient to snuggly hold the cup and to provide room for the outer solution. The chamber is placed in a Faraday cage to electrically isolate it from the outside.

The SR that was used for bilayer experiments was prepared from a crude SR prep which was diluted to $1 \mathrm{mg} / \mathrm{mL}$ in a sucrose/ $\mathrm{CsMeSO}_{3}$ buffer. Planar lipid bilayers were formed with $5 \mathrm{mg} / \mathrm{mL}$ of a 5:3:2 ratio of PE: PS: PC (PE: 1,2-Dioleoyl-sn-Glycero-3Phosphoethanolamine; PS: 1,2-Dioleoyl-sn-Glycero-3-[phosphor-L-Serine]; PC: 1,2Dioleoyl-sn-Glycero-3-phosphocholine) suspended in chloroform. The solvent was evaporated with a stream of $\mathrm{N}_{2}$ gas and resuspended in decane at a final concentration of $70 \mu \mathrm{g} / \mu \mathrm{L}$.

Cesium methane sulfonate $\left(\mathrm{Cs}^{+} \mathrm{CH}_{3} \mathrm{O}_{3} \mathrm{~S}^{-}\right)$buffer was used in all experiments and $\mathrm{Cs}^{+}$is the only membrane permeable charge carrier.

The experiment was started in the presence of 400: $40 \mathrm{mM}$ cis: trans $\mathrm{Cs}^{+} \mathrm{CH}_{3} \mathrm{O}_{3} \mathrm{~S}^{-}$ gradient at a holding potential of $+36 \mathrm{mV}$ to promote the fusion of SR vesicles. Following the fusion, the trans $\mathrm{Cs}^{+}$concentration was brought up to $400 \mathrm{mM}$ to prevent subsequent fusion events.

Traces of not less than $1 \mathrm{~min}$ were recorded and channel output was filtered at 800-1000 Hz. Single channel activity was tested with addition of different modulators to the cis side of the bilayer. All the recorded traces were analyzed using the ClampFit 9.0.

\subsubsection{ANALYSIS}


Analysis of single channels is largely automated in Clampfit 9.0. The calculation of open probability and open and close times will be discussed in this section. These are the two most commonly used methods for analyzing and understanding single channel data.

\section{Event detection}

The major task of the single channel analysis program is to compile event lists. For a single channel analysis, an event is defined as a sudden change in current as the result of the opening or closing of an ion channel. These detected events are characterized and stored in an event table in the result window, which is then used for statistical analysis of channel current amplitudes and channel kinetics. The method adopted by this thesis for event detection uses a half amplitude threshold technique. Every crossing of the threshold is interpreted as an opening or closing of the channel. Moreover, the time spent above the threshold is taken as an estimate of the channel opening time.

\section{Open probability}

$\mathrm{P}_{\mathrm{o}}$ is the fraction of time the channel is in a conducting state. It is calculated from the ratio of the number of data points in a conducting level to the total number of points in the record. A value of 1 means that the channel is always open, while a value of 0 means that the channel is never open.

As all of the open and close times have been measured from event detection analysis, $\mathrm{P}_{\mathrm{o}}$ can be calculated as total open time divided by total length of the record. If there is only 
one open level, this is the same thing as the average current level throughout the record, divided by the open-channel current level.

Clampfit also produces a time dependent graph of open probability. Open probability is almost never stable with time, so it is useful to seeing how long it took for chances to occur and for choosing a representative time period to make figures.

\section{Open and closed time}

The dwell-time distribution provides a more detailed and useful analysis of channel activity. Dwell time means the times spent at each current level before it jumps to a new value. An overall picture of channel gating rates is encapsulated in the mean open and closed dwell-times, referred to as $\tau_{\mathrm{o}}$ and $\tau_{\mathrm{c}}$. Frequency histograms of open and closed dwell-times show the kinetic signature of the gating mechanism, and this distribution can be well described by the sum of decaying exponential functions. There are many ways to display these histograms, among which linear histogram and logarithmic histogram are two common types of plots to use. Logarithmic histograms developed by Sigworth and Sine [28] have been demonstrated a more useful plot [29]. In this method, the probability density, estimated by dividing the number of events in each bin by the bin width, is plotted on a log-log scale along with a log-log plot of the theoretical probability density function. All the single channel data in this thesis were analyzed by using this method. 


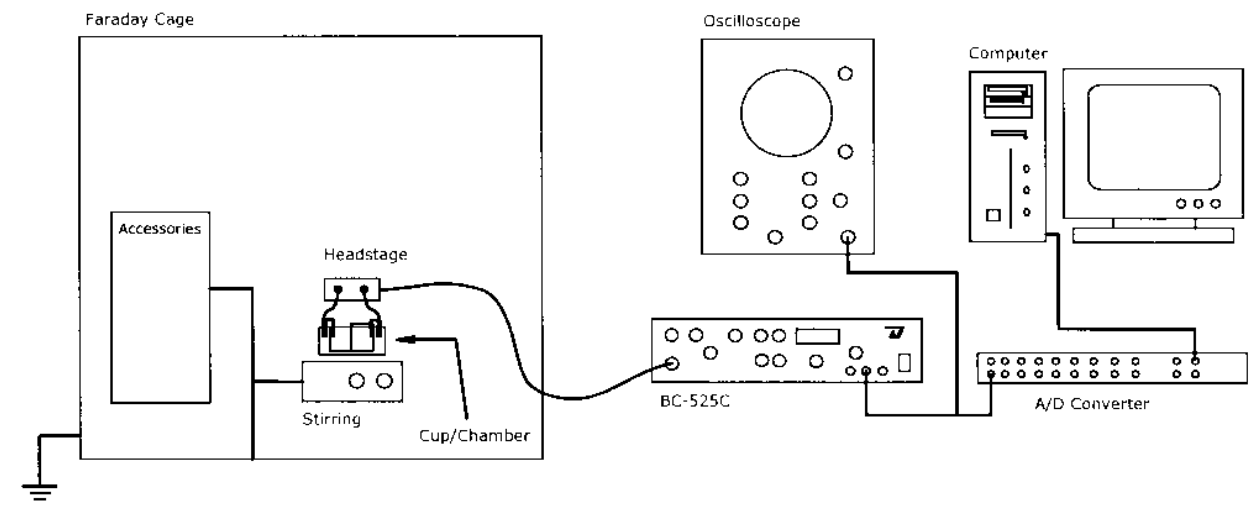

B

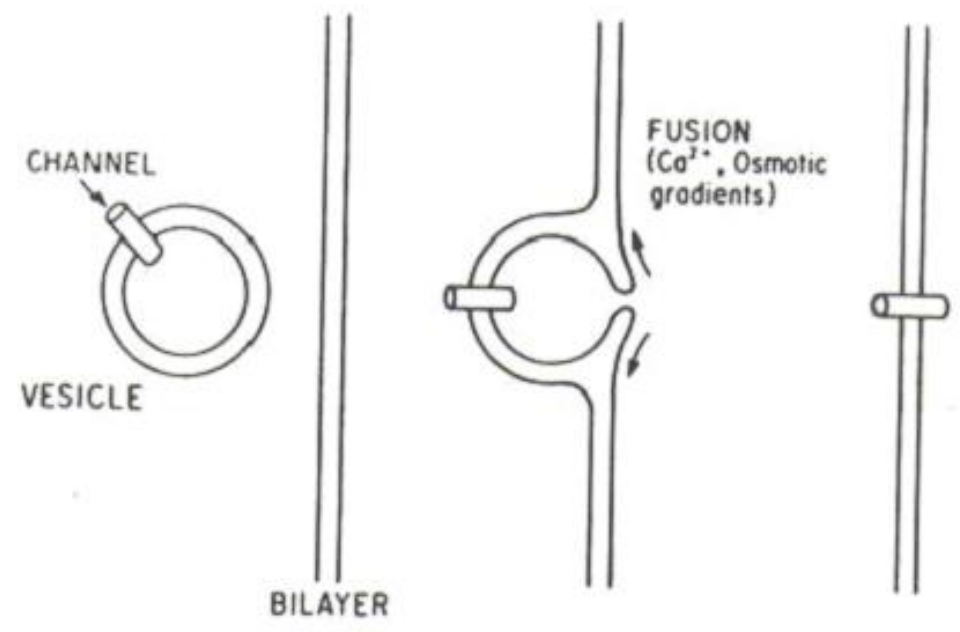

Fig 2.1. A is a schematic representation of the BLM setup in the Abramson lab. B is a schematic showing SR vesicle fusion to the artificial membrane [30]. 


\subsection{STUDENT T TEST}

The student $\mathrm{T}$ test uses the t-distribution that was developed by William Sealy Gosset in 1908. It is often used to compare two small sets of quantitative data when samples are collected independently of one another. The t-test assumes that the observations within each group are normally distributed and the variances are equal in the two groups [31].

In order to perform a t-test on two independent samples which have unequal sample sizes and equal variance, the following equation were used.

$$
t=\frac{\bar{X}_{1}-\bar{X}_{2}}{S_{X_{1} X_{2}} \cdot \sqrt{\frac{1}{n_{1}}+\frac{1}{n_{2}}}}
$$

where

$$
S_{X_{1} X_{2}}=\sqrt{\frac{\left(n_{1}-1\right) S_{X_{1}}^{2}+\left(n_{2}-1\right) S_{X_{2}}^{2}}{n_{1}+n_{2}-2}} .
$$

Where $\mathrm{n}_{1}, \mathrm{n}_{2}, \overline{\mathrm{X}_{1}}, \overline{\mathrm{X}_{2}}$, and $\mathrm{S}_{\mathrm{X} 1}, \mathrm{~S}_{\mathrm{X} 2}$ are sample size, mean value, and standard deviation for group one and two. 


\subsection{DYE PHOTOSENSITIZED ELECTRON DONOR/ ACCEPTOR TEST}

\subsubsection{INTRODUCTION}

The dye photo bleaching experiment relies on the excitation of single electrons in dye molecules to a more reactive state, and on existence of a stable, non-reactive reduced state for quantifying the extent of the reactions. Fig 2.3 shows the basic mechanism involved in this assay. The first step in the reaction pathway is the formation of the high energy singlet state of the dye $\left({ }^{1} D_{\text {De }}{ }^{*}\right)$ by photo excitation with visible light. ${ }^{1}$ Dye ${ }^{*}$ then decays to a triplet state $\left({ }^{3} \mathrm{Dye}^{*}\right)$ spontaneously. Interaction between the triplet states by collision results in the production of short lived cation and anion radicals. In the aqueous solution, two dye anion radicals can interact with each other and form a stable reduced bleached state $\left(\right.$ Dye- $\left.\mathrm{H}_{2}\right)$. However, when there is no electron donor component present, the population of Dye ${ }^{\bullet-}$ and Dye ${ }^{\bullet+}$ is small and they recombine rapidly. Photo bleaching proceeds slowly.

The electron acceptor property of a drug was examined in the presence of a sacrificial electron donor such as NADH or EGTA to increase the initial concentration of dye anion radicals. When there is no acceptor presented, the dye photo bleaching signal and in the presence of $\mathrm{O}_{2}$, the production of superoxide is maximized. Both the bleaching signal and superoxide production decreases after the addition of an electron acceptor. The difference between the rate of superoxide production and the dye bleaching in the presence and absence of the compound of interest is a measure of electron-acceptor activity of the compound. 
In order to see whether a compound is an electron donor, the auxiliary donor was replaced with the reagent to be tested. If the compound tested is an electron donor, dye photo bleaching increases as does the production of superoxide, which is detected with XTT.

Two similar dyes, the thiazine dye methylene blue (MB) and the xanthene dye eosin, were used in the electron donor/acceptor experiments. Both of dyes promote electron transfer and exhibit an excited triplet state when excited by visible light. The selection of which dye should be used in each experiment depends on the relation of dye absorbance spectra to wavelength of interest.

The electron donor properties of FKBP12, K201 and its dioxole derivative, discussed in this paper, were tested using Methylene Blue (MB). Fig2.2 shows the structure of MB and its stable bleached form. $\mathrm{MB}$ has a sharp absorbance peak at $663 \mathrm{~nm}$ due to its conjugated ring structure. 


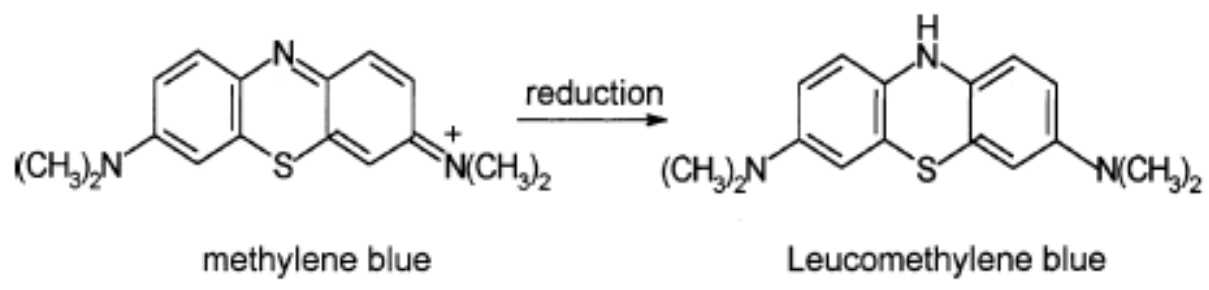

Fig2.2 Initial and reduced structure of Methylene Blue. The conjugation of the rings is disrupted by the reduction resulting in the loss of the visible absorbance peaks [32]. 


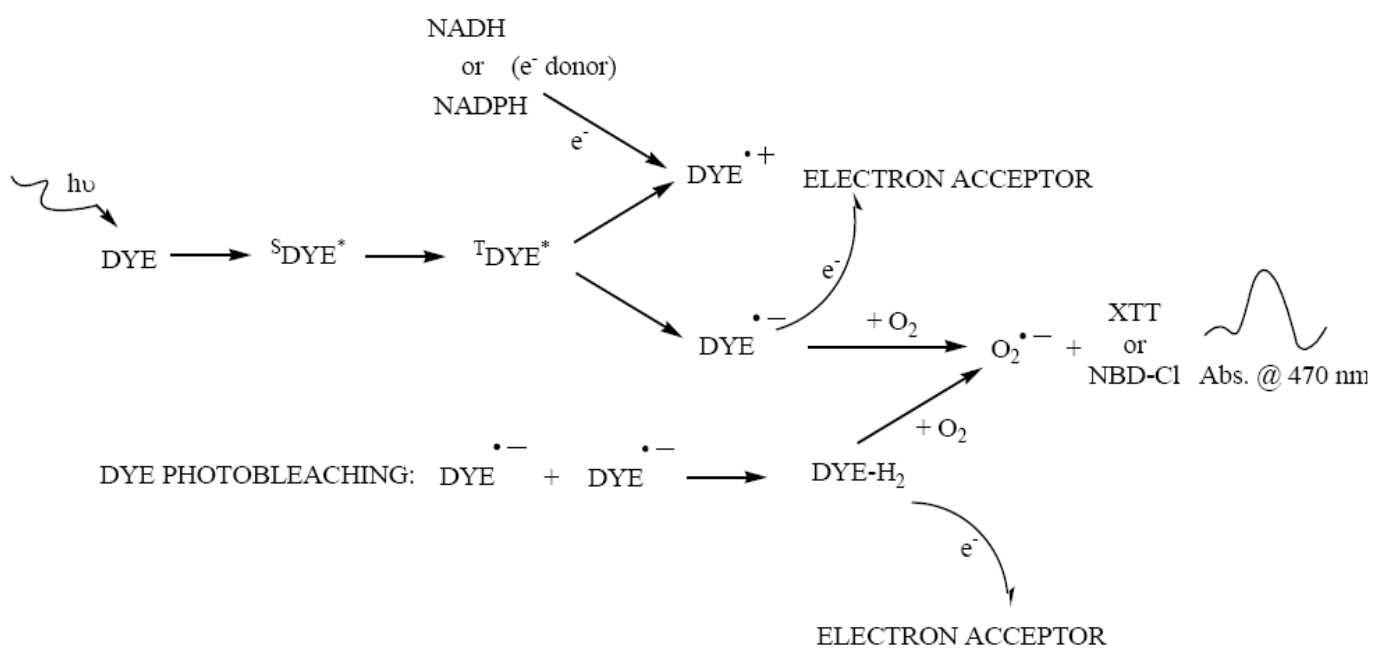

Fig 2.3 Scheme showing the protocol for measuring the electron acceptor/donor properties of reagents [12]. 


\subsubsection{PROTOCOL}

Experiments were carried out in the presence of $\mathrm{O}_{2}$. All electron donor experiments were conducted in $1 \mathrm{mM}$ tris buffer (pH7.4). 20\% DMSO may be required in some donor experiments to avoid dye aggregation effects. MB at concentration of $10 \mu \mathrm{M}$ was used as the excited dye and superoxide production was detected with an optical probe XTT (2, 3Bis(2-methoxy-4-nitro-5-sulfophenyl)-2H-tetrazolium-5-carboxanilide) at $100 \mu \mathrm{M}$. The spectra changes were quantified by measuring the decreased bleaching signal at $663 \mathrm{~nm}$ and the increased absorbance at $470 \mathrm{~nm}$ as a function of time. All measurements are made with respect to a blank cuvette containing only Tris buffer.

HP8452 diode array spectrophotometer was used in all experiments. Illumination was provided by a $50 \mathrm{~W}$ lamp positioned 2-3 $\mathrm{cm}$ above the sample. Measurements could be taken using a standard mode or kinetic mode. Similar result should be obtained with both types of modes. The only difference between these two modes is that in the standard mode, data was manually collected over a time interval fixed by the operator while in the kinetic mode, data was automatically collected by computer at a fixed time intervals.

Initial rates were calculated using Sigmaplot 10.0 by fitting the data to a function called a two parameter exponential rise to maximum. The rate could be automatically calculated by the computer in the kinetic mode. 


\subsection{INTRODUCTION TO ANTIARRYTHMIC DRUGS}

\subsubsection{K201 AND THE DIOXOLE DERIVATIVE OF K201}

K201, also known as JTV519, is a 1, 4-benzothiazepine derivative, which was developed by Kaneko [33] in the mid 1990s. Fig 2.4 shows the chemical structure of K201. It has been proposed that the drug can suppress the development of heart failure by inhibiting spontaneous calcium leakage from SR during the early stages of heart failure [34]. However, it also acts as a multi-channel blocker including $\mathrm{K}^{+}$channels. The block of the inward rectifying $\mathrm{K}^{+}$channel can result in prolongation of the cardiac action potential which is known as a proarrhythmic signal $[35,36]$.

Many efforts have been made to understand the basic mechanism of the action of K201. Some research groups show that the cardio-protective effectiveness is due to its ability to correct the defective FKBP12.6 control of RyR2 [34], while other labs argue for the inhibition effect of K201 on SR CRC being independent of the presence of the FKBP12.6 protein [37]. Data presented in this thesis show that K201 is a strong electron donor and also a potent $\mathrm{Ca}^{2+}$ channel inhibitor independent of the presence or absence of FKBP12.

According to our hypothesis, most channel inhibitors act as electron donors. Selective modification of the electron donor properties of a drug modifies its potency and effectiveness as a CRC inhibitor in a predictable manner. The 1,3dioxole derivative of K201, shown in Fig 2.5, was obtained by selective modification of the chemical structure of K201, resulted in a compound with enhanced electron donor properties. The syntheses 
of the analog are based on published work which involves well-known and efficient chemistry [38] [33]. The data from bilayer experiments show that this derivative of K201 is ten times more effect an inhibitor of RyR1 activity than its parent molecule [39].

Both K201 and its analogs used in this thesis were synthesized by Jorge Escobedo and Jialu Wang from Dr Strongin's Lab at Portland State Unversity.

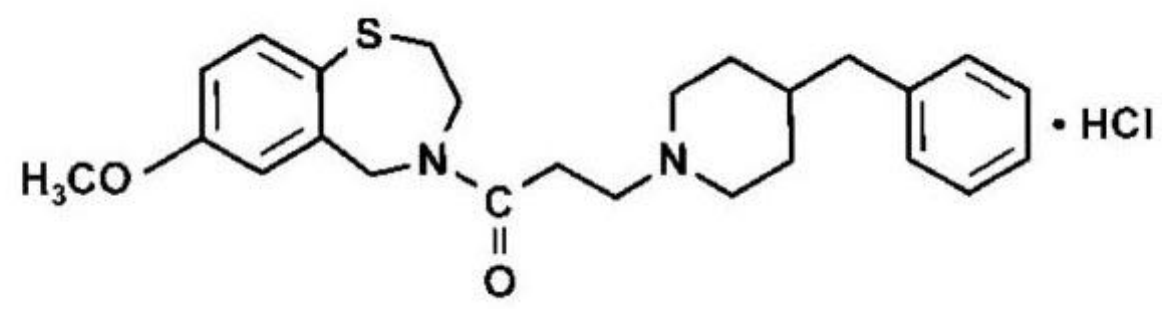

Fig 2.4 Chemical structure of K201, a 4-[3-(4-benzylpiperidin-1-yl)propionyl]-7methoxy-2,3,4,5-tetrahydro-1,4-benzothiazepine monohydeochloride.<smiles>COc1ccc2c(c1)CN(C(=O)CCN1CCC(Cc3ccc4c(c3)OCO4)CC1)CCS2</smiles>

Fig 2.5 Chemical structure of the dioxole derivative of K201 


\subsubsection{4-METHOXY-3-METHYL PHENOL (4-MmC)}

4-MmC is a derivative of 4-chloro-3-methyphenol (4-CmC). It was synthesized using the method reported by Higgins et al [40]. 4-CmC is a clinically proved activator of the intracellular $\mathrm{Ca}^{2+}$ release channel and also inhibits the calcium pump protein from SR at low millimolar concentration [41]. Chemical structures of both compounds are shown in fig 11. By substituting the chloro group with the methoxy group, we turned the electron acceptor 4-CmC into an electron donor, 4-MmC. Our previous study showed that 4-MmC is potent inhibitor of $\mathrm{RyR} 1$, with an the $\mathrm{IC}_{50}$ below $1 \mu \mathrm{M}$ [39].

4-MmC used in this study was synthesized by Dr. Strongin's lab at Portland State University.

4-chloro-3-nethyl phenol (4-CnC) 4-nethoxy-3-nethyl- phenol (4-MmC)
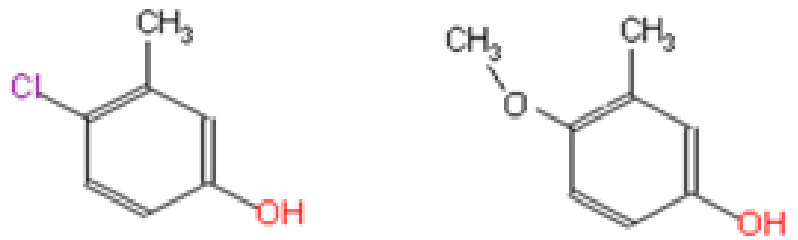

Fig 2.6. Chemical structure of 4-Chloro-m-Cresol and 4-Methoxy-3-methylphenol 


\section{CHAPTER III}

\section{RESULTS}

The single channel recording technique is a very powerful and versatile method for studying electrophysiological properties of biological membranes. It differs from other experiments, such as calcium efflux assays and ryanodine binding assays in that a single molecule is being probed, providing us the opportunity to observe the interaction with a single protein. All of the bilayer reconstitution works described in this study were done with sheep cardiac ventricular muscle SR vesicles which were fused with an artificial membrane as described in section 2.2. The SR vesicles were not exposed to detergent.

In this chapter, the ability of K201, 1, 3 dioxole derivative of K201 and 4-Methoxy-3Methyl phenol in inhibiting the cardiac calcium release channel is examined and compared. Three drugs showed stronger potency in inhibiting the cardiac calcium release channel than the skeletal calcium release channel, and all of them inhibit the calcium release at low micromole concentrations or sub-micromolar concentrations. 


\subsection{K201 INHIBITS CARDIAC CALCIUM RELEASE CHANNEL (RyR2)}

The effect of K201 on single channel activity was tested in the presence of $0.1 \mu \mathrm{M} \mathrm{Ca}^{2+}$ and $1 \mathrm{mM}$ ATP added to the cis chamber of the bilayer setup, a condition that mimics the physiological environment in the cell. Different doses of K201 ranging from $50 \mathrm{nM} 10$ $\mu \mathrm{M}$, were added to the cis chamber, which corresponds to the outside face of SR (the cytoplasmic face). Six independent experiments were carried out under identical conditions. Fig 3.1 shows representative traces with addition of 0, 0.5, 1, $10 \mu \mathrm{M}$ K201. There are two channels fused into the artificial membrane. The open probability $\left(\mathrm{P}_{\mathrm{o}}\right)$ was calculated from Clampfit as described in Chapter 2. As more than one channel present at the same time, the $\mathrm{NP}_{\mathrm{o}}$ for the trace is simply the sum of $\mathrm{P}_{0} \mathrm{~s}$ for each channel. The open probability for control (Fig3.1 A) is $36.6 \%$. K201 $(0.5 \mu \mathrm{M})$ decreases the channel open probability to less than $15 \%$. As shown, the open probability decreases as the K201 concentration increases. The channel activity decreases dramatically at low drug concentrations ranging from $50 \mathrm{nM}$ to $1 \mu \mathrm{M}$. Addition of $\mathrm{K} 201$ at concentrations $>5 \mu \mathrm{M}$ maximally inhibited the channel to less than $20 \%$ of control activity (Fig 3.2).

In fig 3.2, normalized average open probabilities were plotted versus drug concentration and fit to a four parameter logistic curve in Sigma Plot 10. The $\mathrm{IC}_{50}$, the drug concentration that half inhibits release channel activity, is $1.13 \pm 0.68 \mu \mathrm{M}$, which is $1 / 3$ of the $\mathrm{IC}_{50}$ observed to inhibit RyR1. 


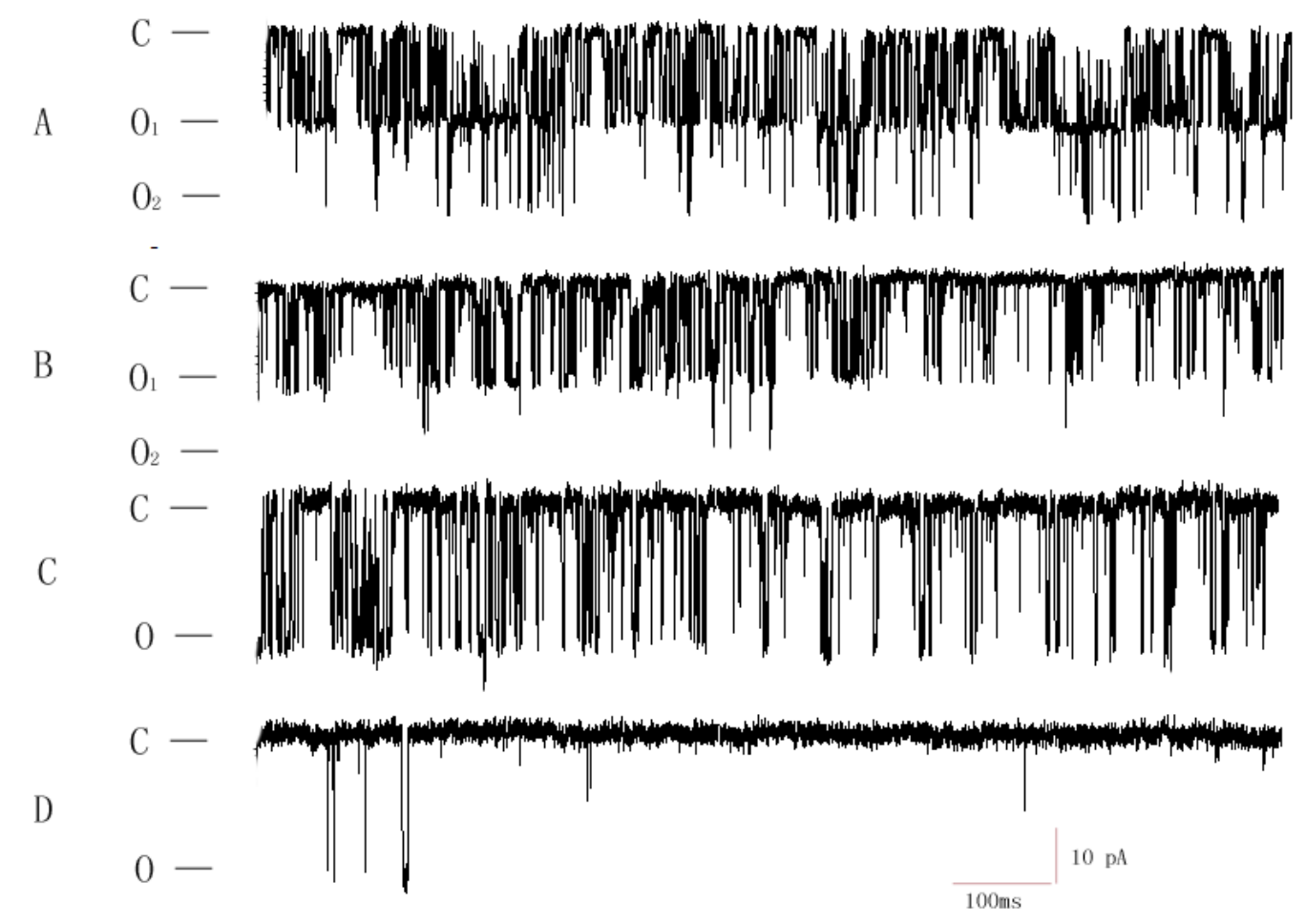

Fig 3.1 RyR2 is inhibited by K201

Representative traces of RyR2 channel activity at $0.1 \mu \mathrm{M}$ free $\left[\mathrm{Ca}^{2+}\right], 1 \mathrm{mM}$ ATP on cis side: $400 \mathrm{mM} \mathrm{CsMeSO}$ on both side of the bilayer and $-36 \mathrm{mV}$ holding potential. $2 \mathrm{~s}$ representative trace excerpts are shown. Open probabilities were obtained from traces recorded for one minute. A: control, $\mathrm{P}_{\mathrm{o}}=36.6 \%$; $\mathrm{B}: 0.5 \mu \mathrm{M} \mathrm{K} 201, \mathrm{P}_{\mathrm{o}}=12.4 \%$; C: $1 \mu \mathrm{M}$ $\mathrm{K} 201, \mathrm{P}_{\mathrm{o}}=10.0 \%$; $\mathrm{D}: 10 \mu \mathrm{M} \mathrm{K201}, \mathrm{P}_{\mathrm{o}}=0.5 \%$. (C- close state; $\mathrm{O}_{1^{-}}$open state for the first channel; $\mathrm{O}_{2}-$ open state for the second channel.) 


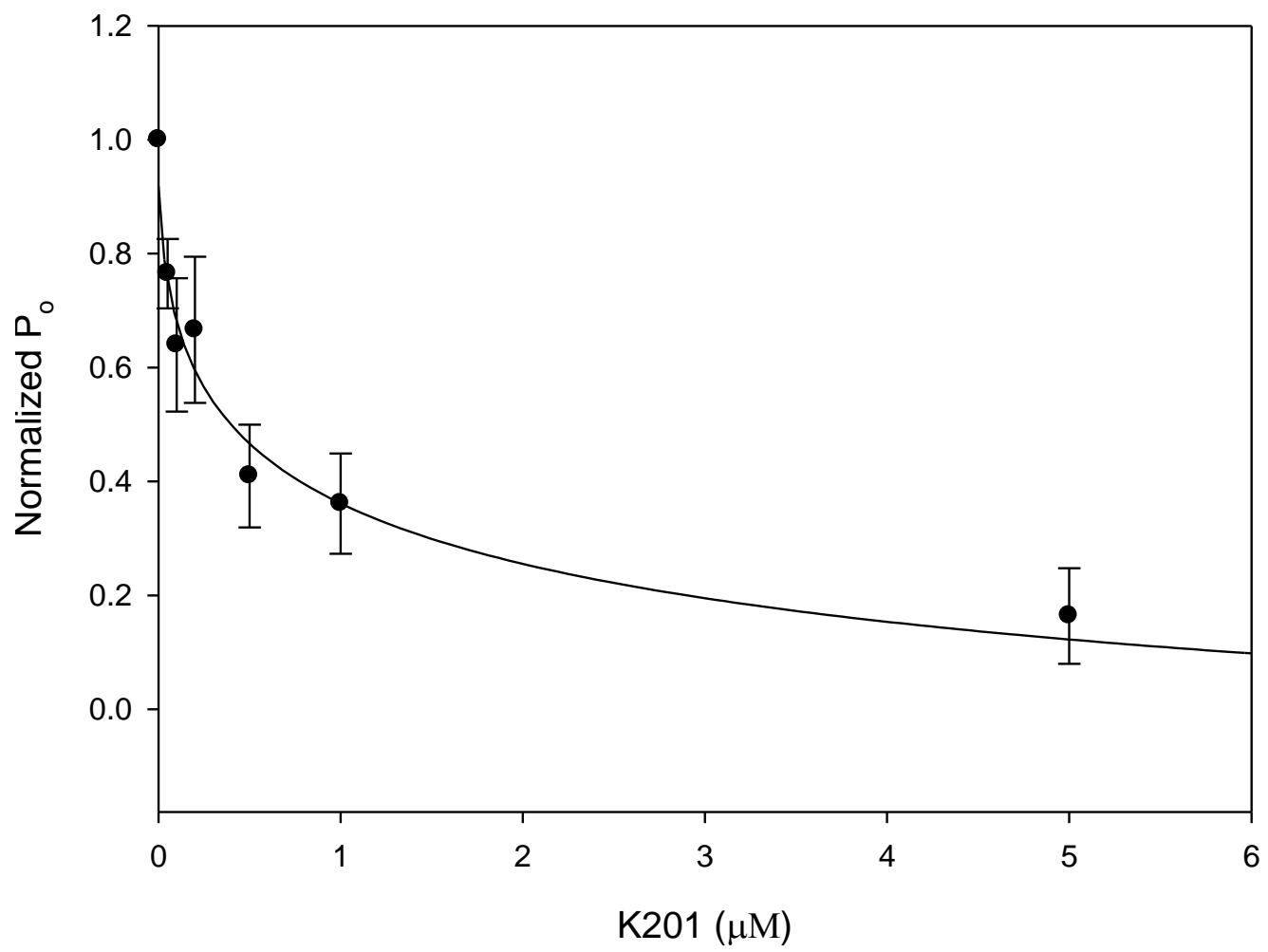

Fig 3.2 Concentration dependent inhibition of RyR2 by K201

This graph was generated from data such as that presented in Fig 3.1. Open probability normalized to 1.0 for control is plotted vs. $[\mathrm{K} 201](\bullet)$. Plots are representative of 6 independent experiments. Error bars shown are the SE. 


\subsection{THE DIOXOLE DERIVATIVE OF K201 IS A MORE POTENT INHIBITOR OF RYR2 THAN K201}

In a previous study, we showed that the dioxole derivative of K201 is a stronger electron donor than is K201[39]. In this section, the inhibitory effect of the dioxole derivative of K201 was tested on the calcium release channel (RyR2) isolated from sheep heart sarcoplasmic reticulum. It is shown to inhibit single channel activity at lower concentrations than K201, and it shows a similar concentration dependent inhibition of RyR2 as was observed on RyR1 (Fig3.8).

The same experimental conditions were used as in testing K201. Concentrations of the dioxole derivative ranging from $0 \sim 10 \mu \mathrm{M}$ were added to the cis chamber of RyR2 channels incorporated into an artificial at concentrations of $0,0.05,1$ and $5 \mu \mathrm{M}$ (fig 3.3). Fig 3.3 shows representative traces of 5 independent experiments carried out under the same condition. An inhibition of the single channel activity was frequently observed following an addition of the $\mathrm{K} 201$ derivative at concentrations as low as $50 \mathrm{nM}$. Addition of $0.5 \mu \mathrm{M}$ of the dioxole derivative of K201 suppressed channel activity by approximately $50 \%$ (Open probability was decreased from $9.9 \%$ to $4.8 \%$ ). The open probability decreased to $\sim 5 \%$ of control as drug concentration increased up to $5 \mu \mathrm{M}$. No further inhibition was observed at higher drug concentrations.

In figure 3.4, the normalized average open probabilities were plotted versus drug concentration and fitted to a four parameter logistic curve in Sigma Plot 10.0. The $\mathrm{IC}_{50}$, the drug concentration that half maximally inhibited release channel activity, was 
$0.4 \pm 0.18 \mu \mathrm{M}$. Compared with the $\mathrm{IC}_{50}$ for $\mathrm{K} 201$, the dioxole derivative was 2.5 times more potent in inhibiting the cardiac CRC than was K201. 


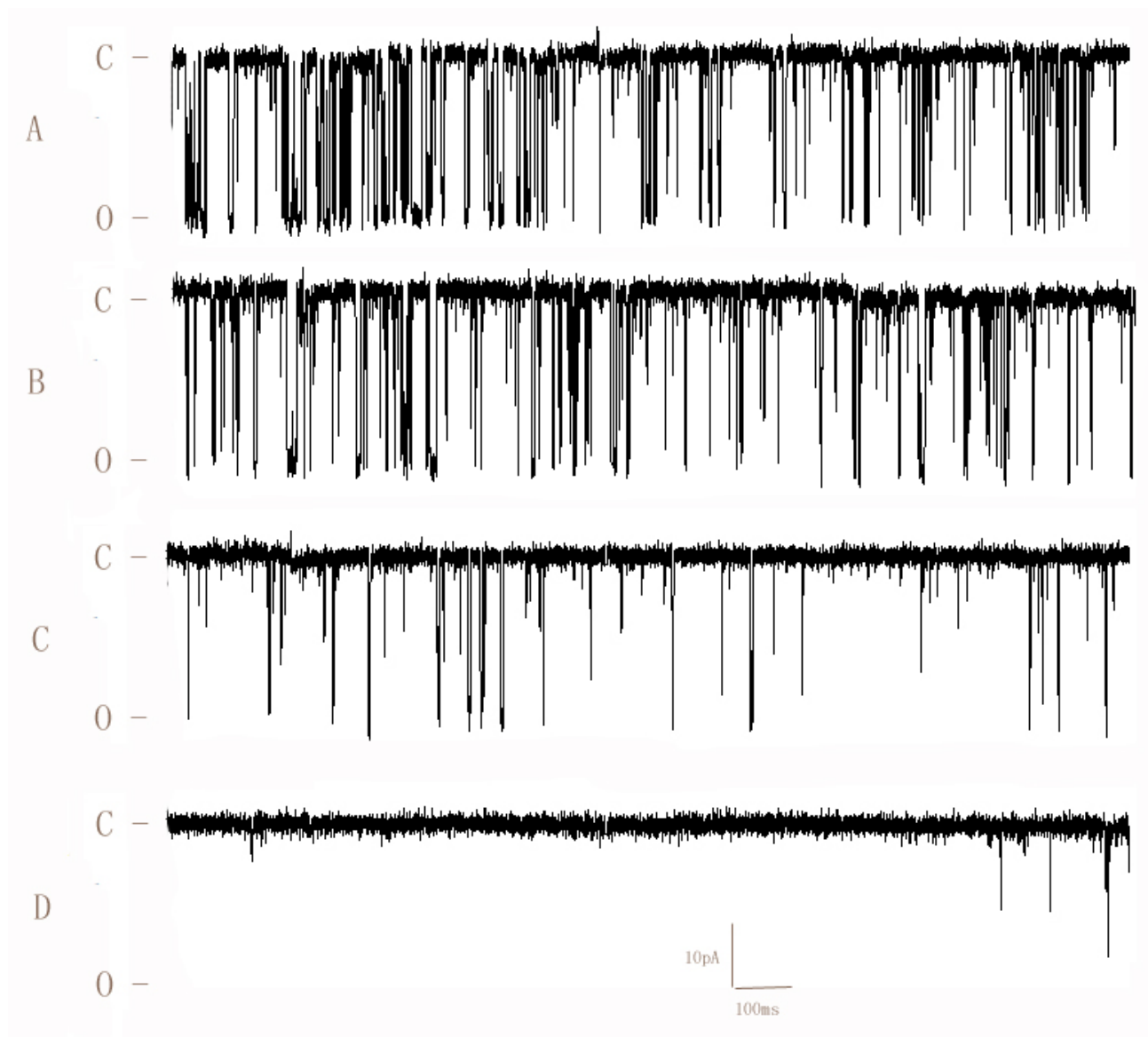

Fig 3.3 RyR2 is inhibited by the 1,3 dioxole derivative of K201

Representative traces of RyR2 channel activity at $0.1 \mu \mathrm{M}$ free $\left[\mathrm{Ca}^{2+}\right], 1 \mathrm{mM}$ ATP on cis side: $400 \mathrm{mM} \mathrm{CsMeSO}{ }_{4}$ on both sides of bilayes and $-36 \mathrm{mV}$ holding potential. $2 \mathrm{~s}$ representative trace excerpts are shown. Open probabilities were obtained from traces recorded for one minute. $\mathrm{A}$ : control, $\mathrm{P}_{\mathrm{o}}=9.9 \%$; $\mathrm{B}: 50 \mathrm{nM}$ of the dioxole derivative of $\mathrm{K} 201, \mathrm{P}_{\mathrm{o}}=8.2 \%$; $\mathrm{C}: 1 \mu \mathrm{M}$ of the dioxole derivative of $\mathrm{K} 201, \mathrm{P}_{\mathrm{o}}=2.0 \%$; D: $5 \mu \mathrm{M}$ the dioxole derivative of $\mathrm{K} 201, \mathrm{P}_{\mathrm{o}}=0.04 \%$. (C- close state; $\mathrm{O}_{1}$ - open state for the first channel.) 


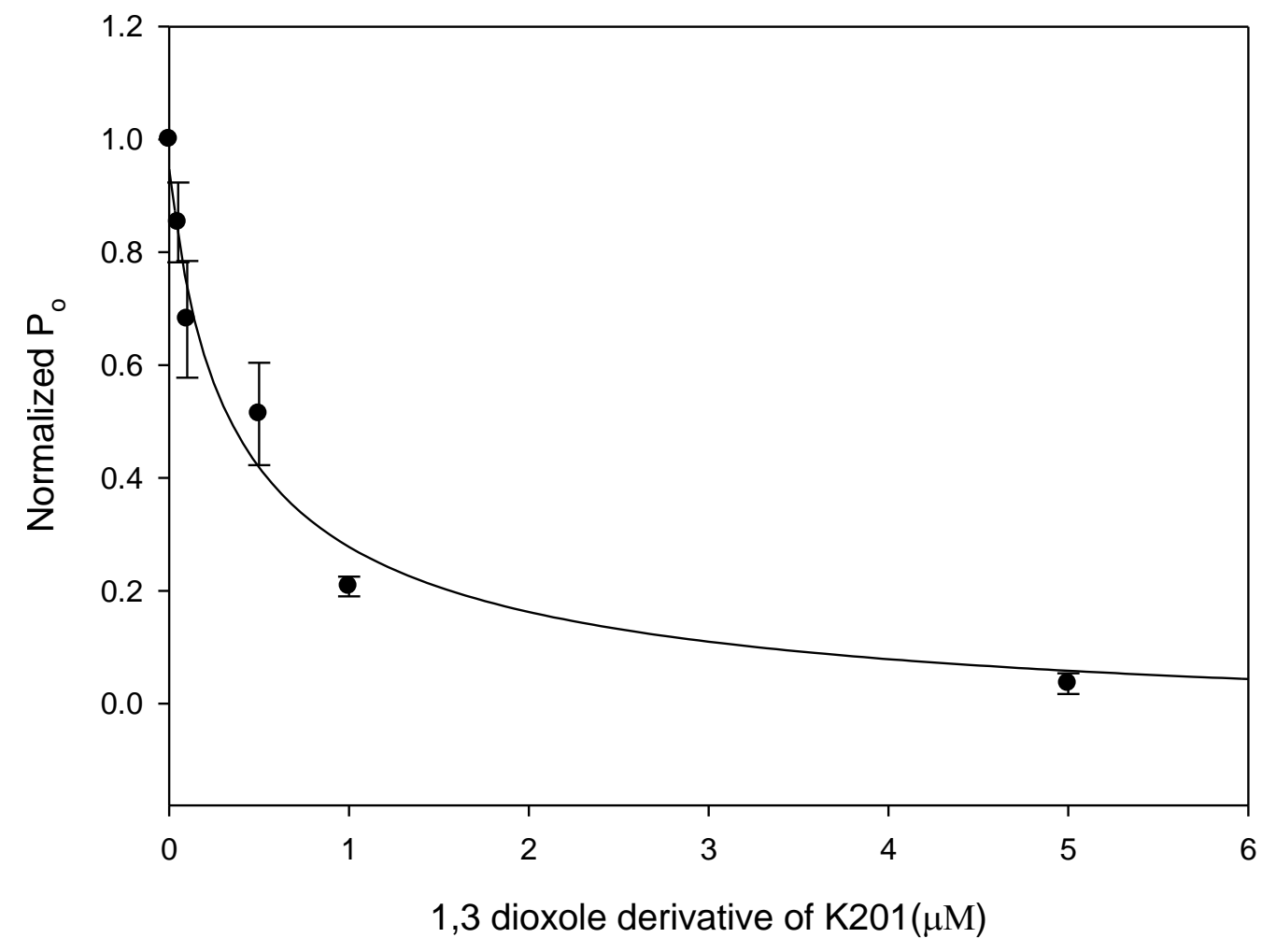

Fig 3.4 Concentration dependent inhibition of RyR 2 by the 1,3 dioxole derivative of K201

This graph was generated from traces similar to Fig 3.3. Open probability normalized to 1.0 for traces is plotted vs. [1,3 dioxole derivative of K201] (•). Plots are representative of at 5 independent experiments. Data shown is the mean \pm SE. 


\subsection{4-METHOXY-3-METHYL- PHENOL INHIBITS RYR2 AT LOWER SALT CONCENTRATIONS}

We have previously shown that 4-Methoxy-3-Methyl phenol (4-MmC) inhibits the RyR1 at low sub-micromolar concentration in a high salt environment [39]. In this section, the inhibitory effect of the 4-MmC was tested on the cardiac calcium release channel under two different conditions at a relatively low salt concentration and at a high salt concentration. Fig 3.8 shows $4-\mathrm{MmC}$ is a more potent inhibitor of RyR2 than is $\mathrm{K} 201$ or its dioxole derivative when bilayer experiments with $4-\mathrm{MmC}$ are carried at low salt concentrations. However, activation of the calcium release was observed at high salt concentration with additions of 4-MmC.

The effect of 4-MmC on single channel activity was tested using the protocol described in section 2.2 except that the cesium methanesulfonate concentration was reduced to 250 $\mathrm{mM}$ instead of $400 \mathrm{mM}$. Additions of $0.1 \mu \mathrm{M} \mathrm{Ca}^{2+}$ and $1 \mathrm{mM}$ ATP were added to the cis chamber of the bilayer setup to mimic the physiological environment in the cell. Different doses of 4-MmC ranging from $50 \mathrm{nM} \sim 10 \mu \mathrm{M}$, were added to the cis chamber. Four representative traces at 4-MmC concentrations of $0,0.05,1$ and $10 \mu \mathrm{M}$ were presented in fig 3.5. An inhibition of single channel activity was observed following an addition of 4$\mathrm{MmC}$ at concentrations as low as $50 \mathrm{nM}$. The addition of $0.1 \mu \mathrm{M}$ 4-MmC suppressed channel activity by around 40\% (Open probability decreased from 50.0\% to $30.0 \%$ ). The open probability was decreased even more as the drug concentration increases up to 1 $\mu \mathrm{M}$. No further inhibition was observed at higher drug concentrations. 
In figure 3.6, the normalized average open probabilities were plotted versus drug concentration and fit to a four parameter logistic curve in Sigma Plot 10.0. The $\mathrm{IC}_{50}$, the drug concentration that half maximally inhibits release channel activity, is $0.14 \pm 0.04 \mu \mathrm{M}$. Compared with the $\mathrm{IC}_{50}$ for $\mathrm{K} 201$ and 1,3 dioxole derivative of $\mathrm{K} 201$, the 4-MmC is a more potent inhibitor of RyR2.

In contrast, fig 3.7 shows that the 4-MmC activates the calcium release channel at high salt concentration $(400 \mathrm{mM})$. The normalized average open probabilities were plotted versus drug concentrations. Each data point is representative of at least 5 experiments. With the addition of 50nM 4-MmC, the channel open probability was increased by more than a factor of two. Further activation was observed at higher drug concentration. 

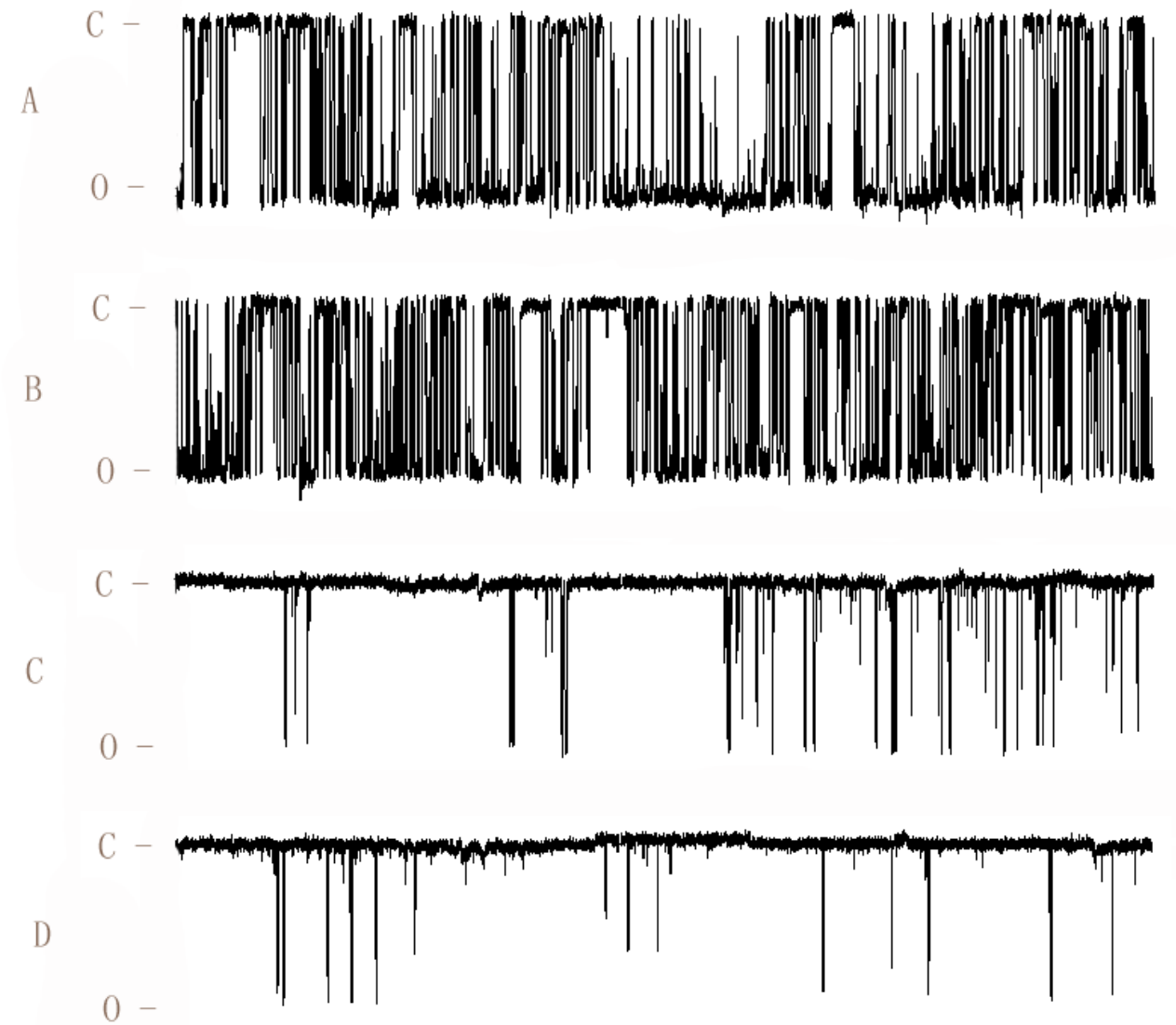

Fig 3.5 RyR2 inhibited by the 4-methoxy-3-methyl-phenol at relatively low salt concentration

Representative traces of RyR2 channel activity at $0.1 \mu \mathrm{M}$ free $\left[\mathrm{Ca}^{2+}\right], 1 \mathrm{mM}$ ATP added to cis side: $250 \mathrm{mM} \mathrm{CsMeSO}$ on both sides of the lipid bilayer and $-36 \mathrm{mV}$ holding potential. 2 s representative trace excerpts are shown. Open probabilities were obtained from traces recorded for one minute. A: control, $\mathrm{P}_{\mathrm{o}}=50.0 \%$; $\mathrm{B}: 50 \mathrm{nM} 4-\mathrm{MmC}, \mathrm{P}_{\mathrm{o}}=35.9 \%$; $\mathrm{C}: 1 \mu \mathrm{M} 4-\mathrm{MmC}, \mathrm{P}_{\mathrm{o}}=1.9 \%$; $\mathrm{D}: 10 \mu \mathrm{M} 4-\mathrm{MmC}, \mathrm{P}_{\mathrm{o}}=0.4 \%$. (C- close state; $\mathrm{O}$ - open state.) 


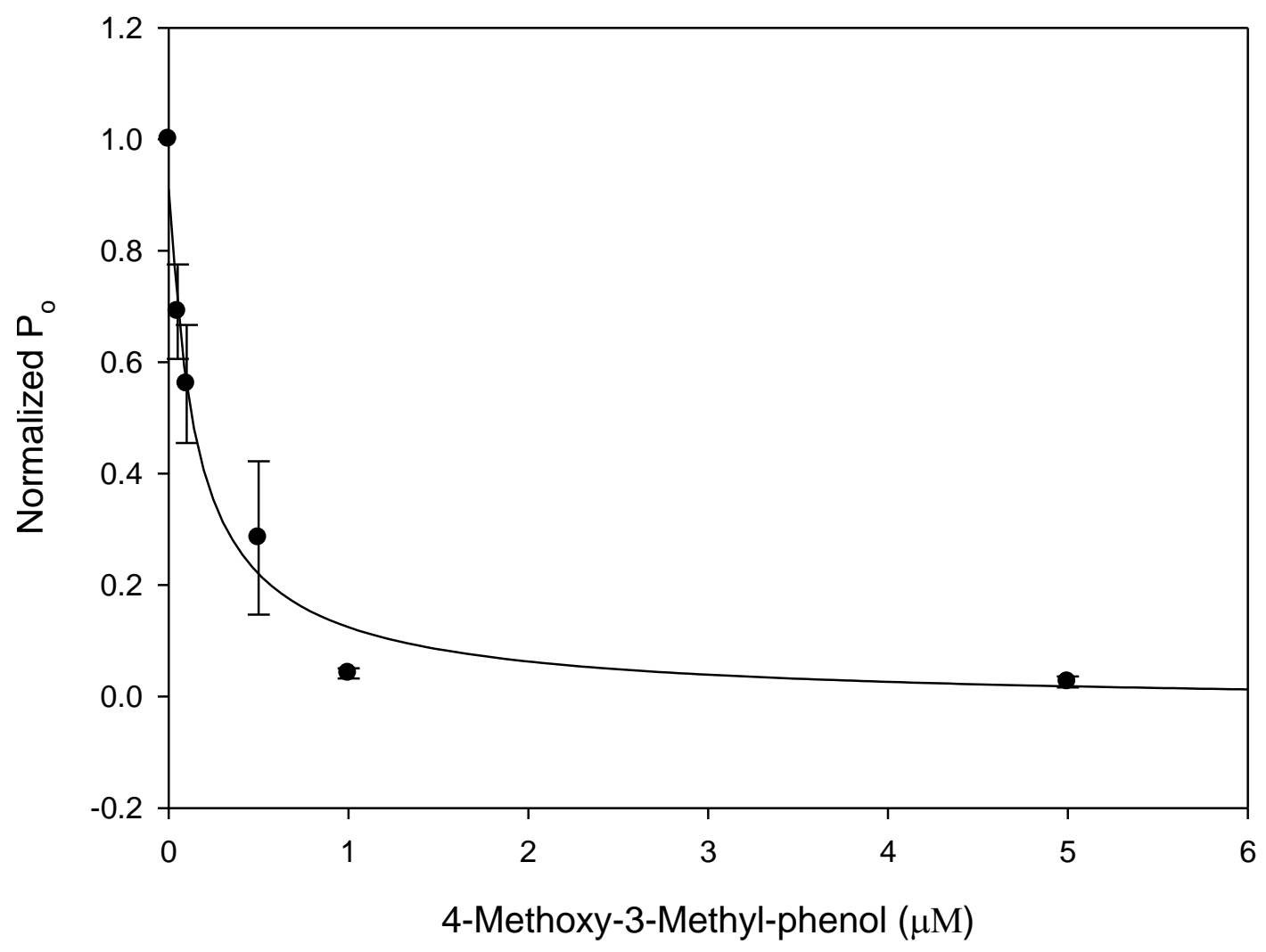

Fig 3.6 4-methoxy-3-Methyl-phenol is a potent inhibitor of the RyR2 at low salt concentrations

This graph was generated from the data similar to that shown in Fig 3.5. Open probability normalized to 1.0 for control, traces is plotted vs. [4-methoxy-3-Methyl-phenol] (•). Plots are derived from the average $+/$ - SE from 5 independent experiments. 


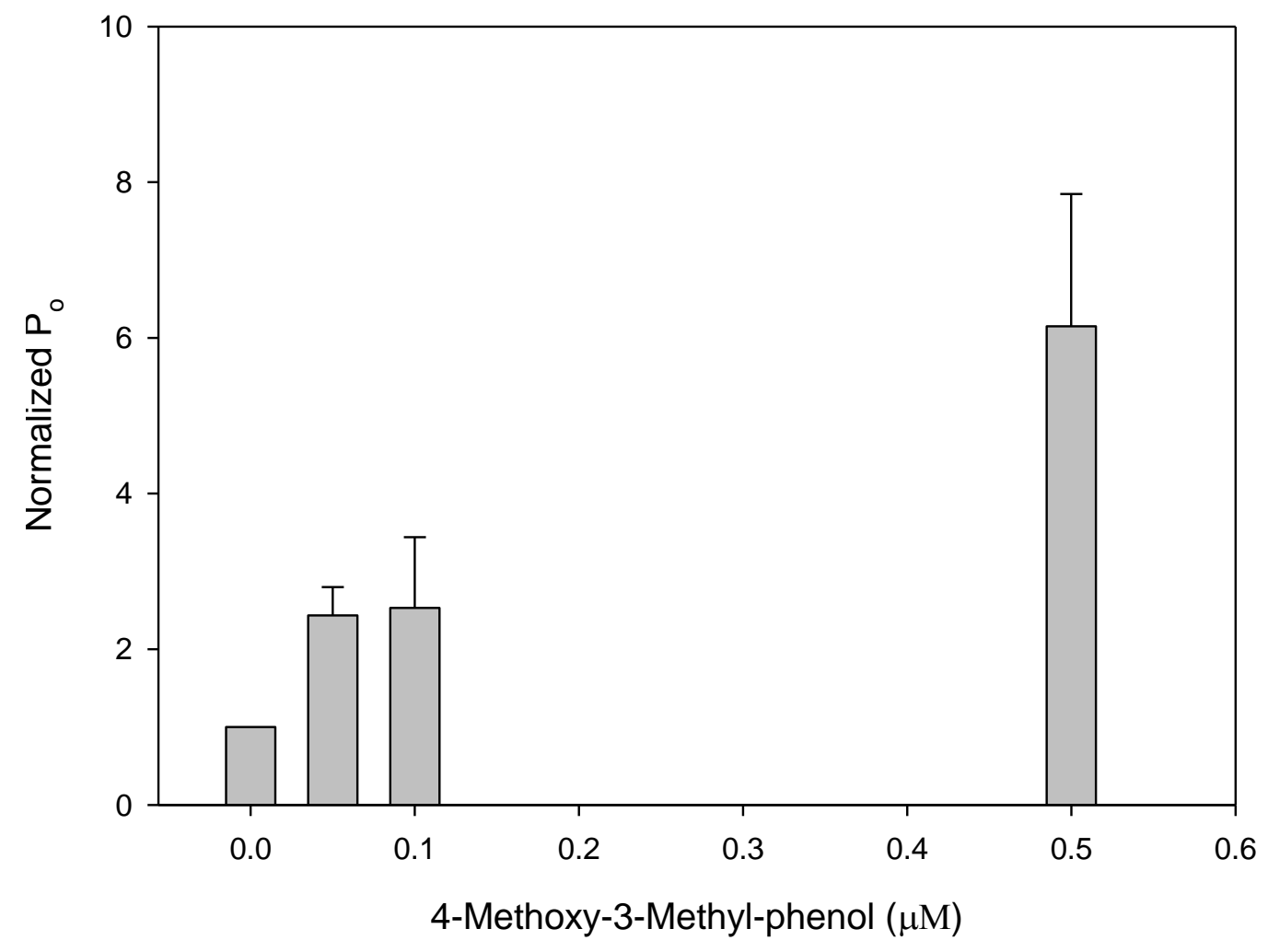

Fig 3.7 4-methoxy-3-methyl-phenol activates the cardiac CRC at high salt concentrations

Open probability normalized to 1 is plotted vs. [4-methoxy-3-Methyl-phenol]. Data shown is the average normalized $P_{o} \pm S E(n=5)$. 


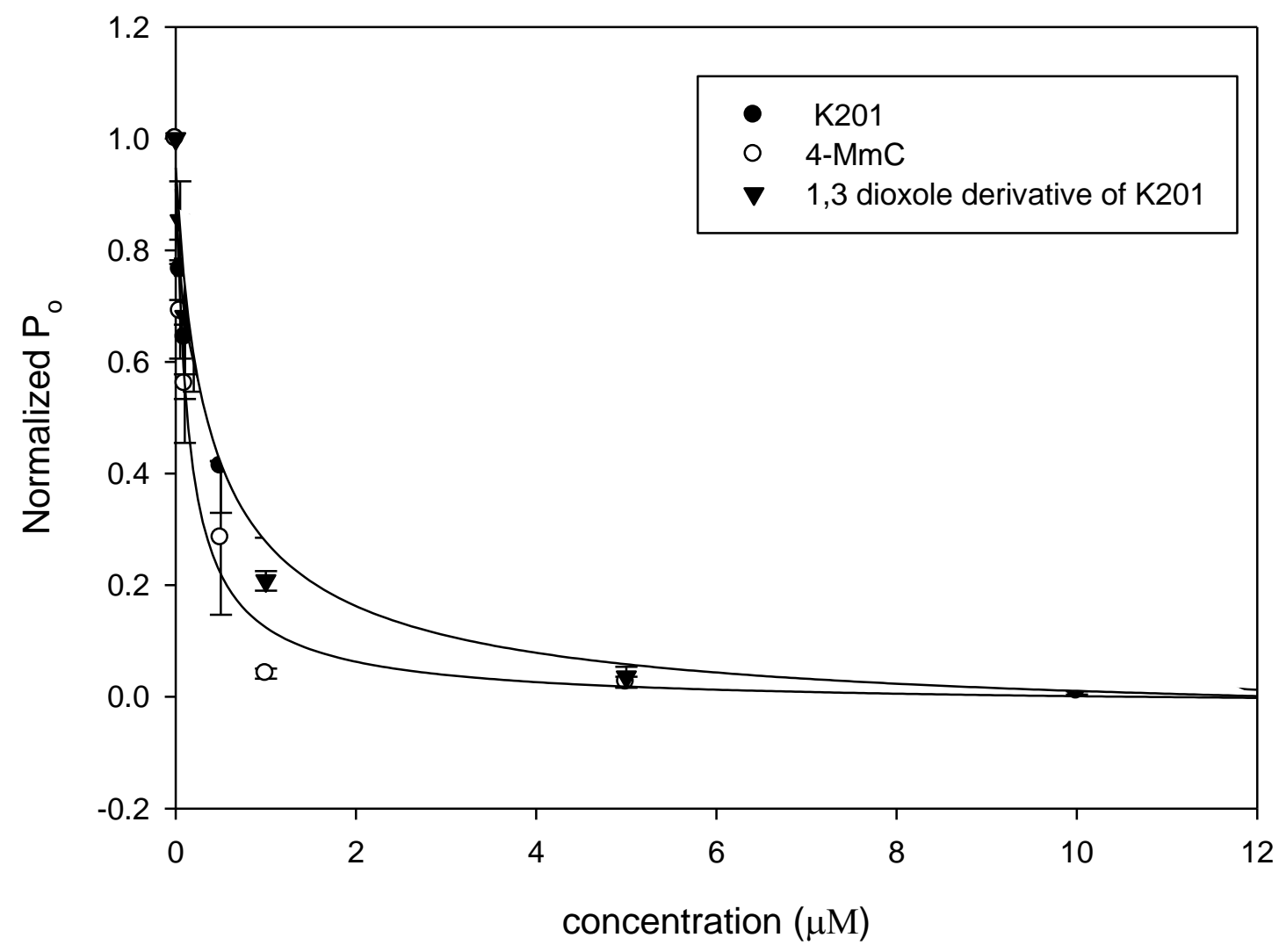

Fig 3.8 Comparison of inhibitory potency of three drugs on RyR2

This graph was generated from the data shown in Fig 3.2, 3.4 and 3.6. Open probability normalized to 1.0 for control, traces are plotted vs. K201(o), 1,3 dioxole derivative of $\mathrm{K} 201(\bullet)$ and 4-MmC( $\boldsymbol{\nabla})$ concentrations. Plots are derived from the average +/- SE from 5 independent experiments. 


\subsection{THREE DRUGS DECREASE THE CHANNEL OPEN PROBABILITIES AND OPEN TIMES BUT DON'T AFFECT THE CHANNEL CLOSE DURATION}

It has recently been shown that the beneficial actions of drugs as RyR2 inhibitors stem from their ability to block RyR2 channels only in the open state.[42] For the three drugs that we studied in this project, they all showed decreases in open probability and open time without significantly increasing the channel closed time at concentration less than the $\mathrm{IC}_{50}$. Average closed times for channels were calculated using the method described in section 2.2.3.

Fig 3.9 and 3.10 shows the closed and open time for K201 at concentrations less than their $\mathrm{K}_{\mathrm{i}}$ (less than or approximately equal to their $\mathrm{IC}_{50}$ ). The addition of $1 \mu \mathrm{M} \mathrm{K} 201$ reduced the channel open probability by more than half and open time by $50 \%(\mathrm{p}=0.08)$, but doesn't significant change the closed duration $(\mathrm{p}=0.97)$. At higher drug concentrations, channel average close state duration increased by a factor of more than 100 compared to control (not shown). The absolute value of average closed time and open time for controls are equal to $4.8 \pm 2.4 \mathrm{~ms}$ and $2.1 \pm 0.6 \mathrm{~ms}$, respectively.

Similar results were obtained with the dioxole derivative of K201 and 4-MmC. In fig 3.11 and 3.12, we show that the dioxole derivative of K201, in a manner similar to K201, shows no signifivant effect on the closed time $(\mathrm{p}=0.45)$ of $\mathrm{RyR} 2$ at concentration as high as $0.5 \mu \mathrm{M}$ (where Po has decreased to $\sim 50 \%$ ), while open time decreased by around $40 \%$ $(\mathrm{p}=0.049)$ The absolute values of the average closed time and open time for controls are $12.3 \pm 3.9 \mathrm{~ms}$ and $1.6 \pm 0.6 \mathrm{~ms}$, respectively. Fig 3.13 and 3.14 show the open time and 
close time change with the addition of $4-\mathrm{MmC}$. The same trend was observed as K201 and the dioxole derivative of $\mathrm{K} 201$ ( $\mathrm{p}=0.42$ for the close time and $\mathrm{p}=0.034$ for the open time at $1 \mu \mathrm{M} \mathrm{K} 201)$. The absolute value of average closed time and open time for controls are $1.5 \pm 0.4 \mathrm{~ms}$ and $2.1 \pm 0.8 \mathrm{~ms}$, respectively. 


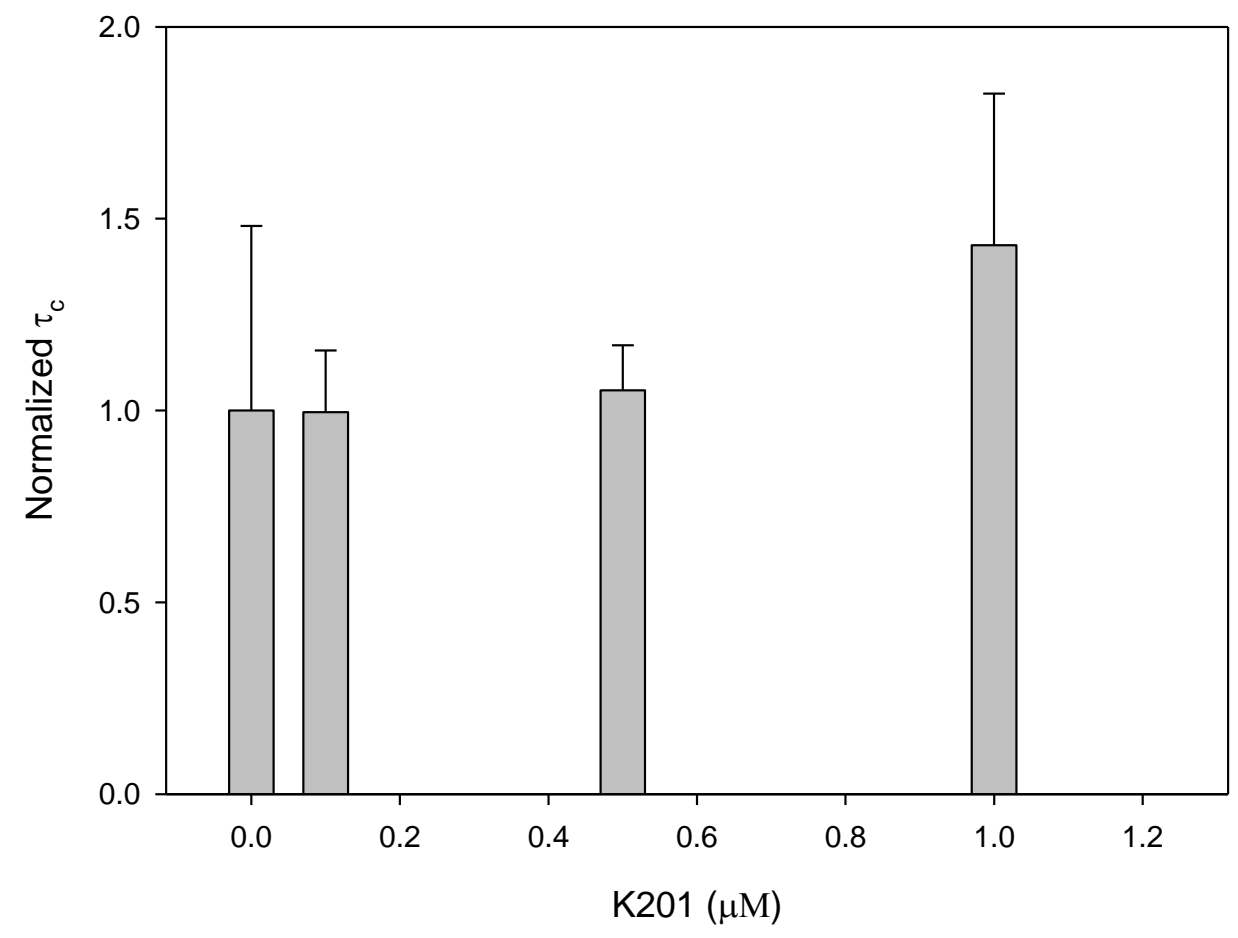

Fig 3.9 K201 has no significant effect on channel closed time $\left(\tau_{\mathrm{c}}\right)$.

Normalized average closed time vs. concentration of the dioxole derivative of K201. Absolute value of average closed time for control is $4.8 \pm 2.4 \mathrm{~ms}$. Each points represents the average of at least four measurements \pm standard error. 


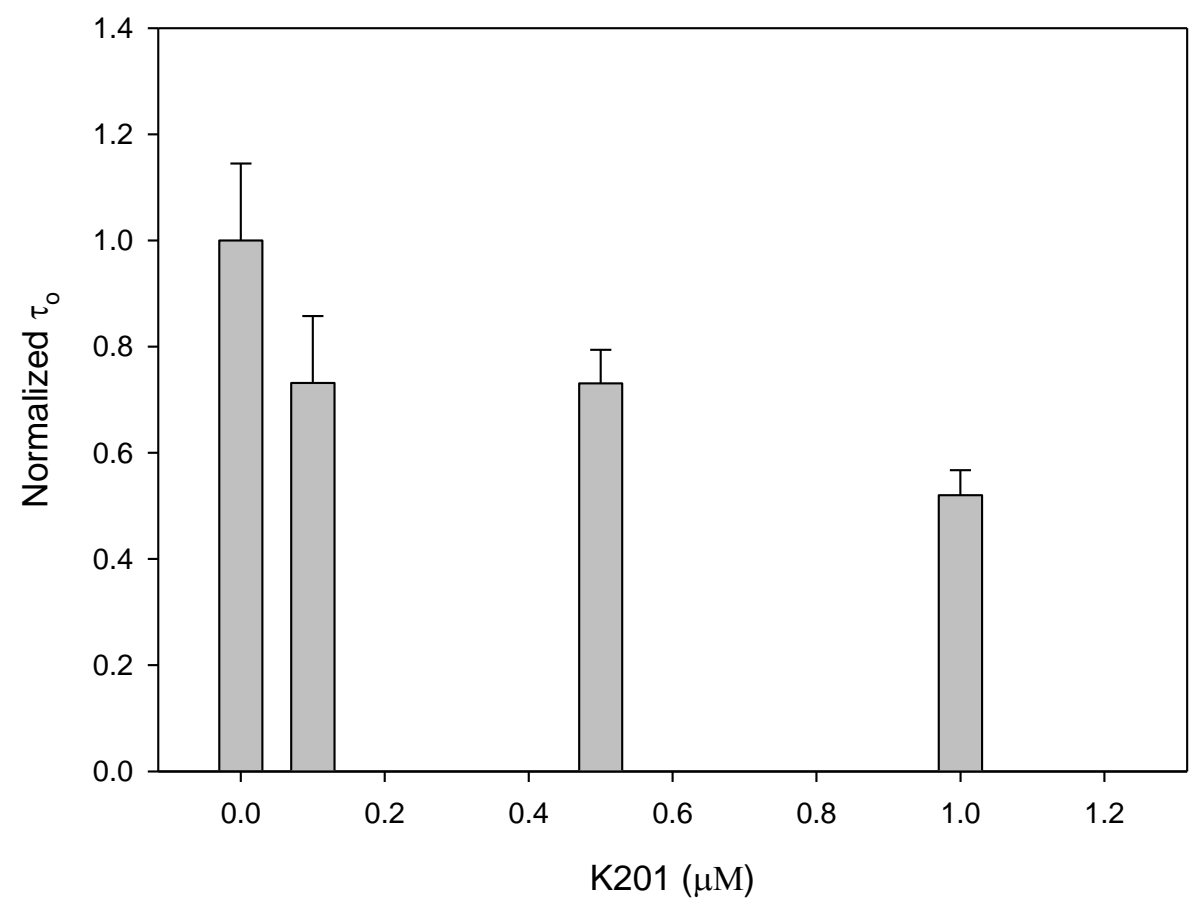

Fig 3.10 K201 decreases channel open times $\left(\tau_{0}\right)$.

Normalized average open time vs. concentration of K201. Absolute value for average open time for control is $2.5 \pm 0.6 \mathrm{~ms}$. Each points represents the average of at least four measurements \pm standard error. 


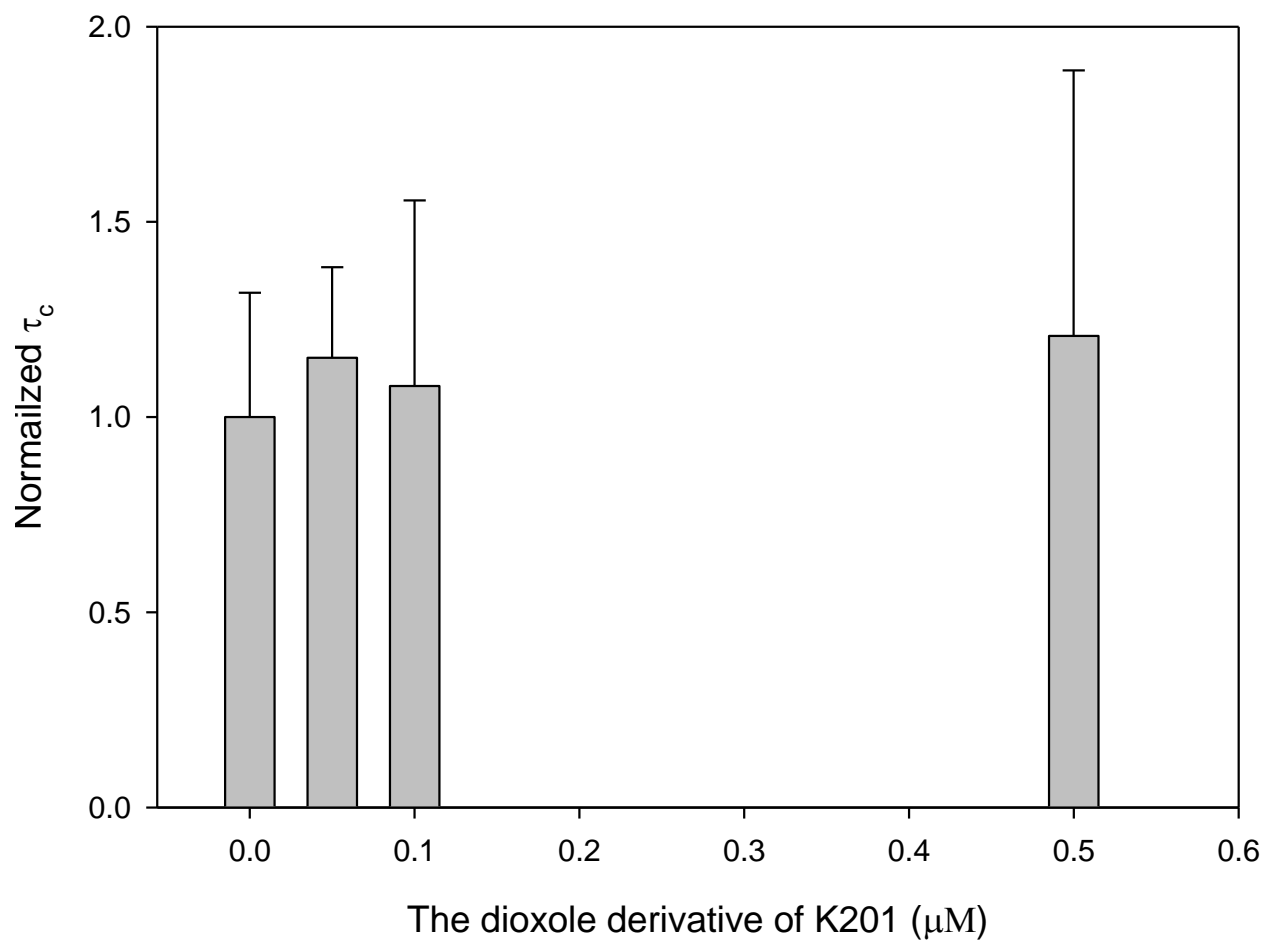

Fig 3.11 1,3 dioxole derivative of K201 has no significant effect on channel closed time $\left(\tau_{\mathrm{c}}\right)$.

Normalized average closed time vs. concentration of the dioxole derivative of K201. Absolute value for average closed time for control is $12.3 \pm 3.9 \mathrm{~ms}$. Each points represents the average of at least four measurements \pm standard error. 


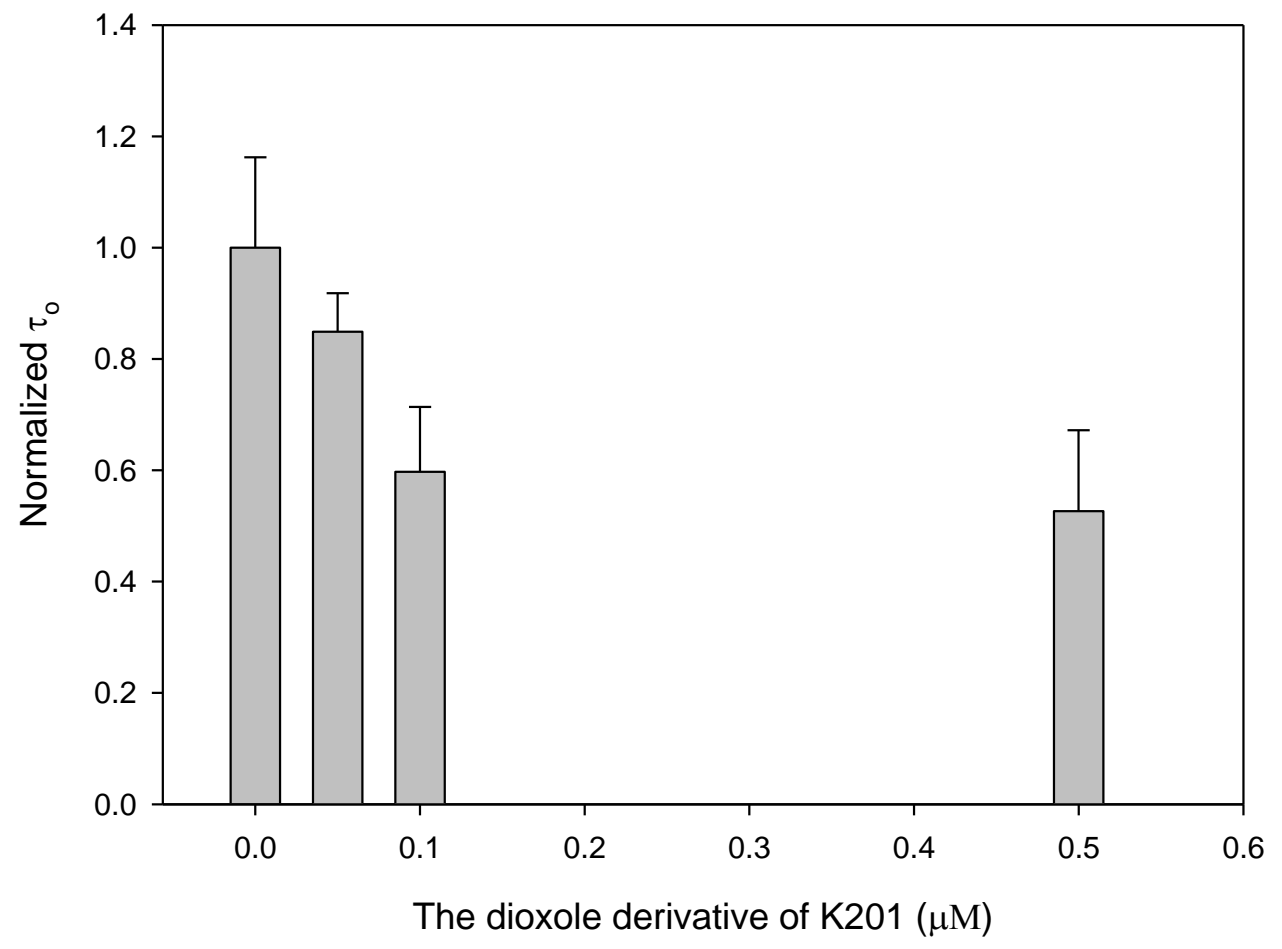

Fig 3.12 1,3 dioxole derivative of K201 decreases channel open times $\left(\tau_{\mathrm{o}}\right)$.

Normalized average open time vs. concentration of the dioxole derivative of K201. Absolute value for average open time for control is $2.5 \pm 0.8 \mathrm{~ms}$. Each points represents the average of at least four measurements \pm standard error. 


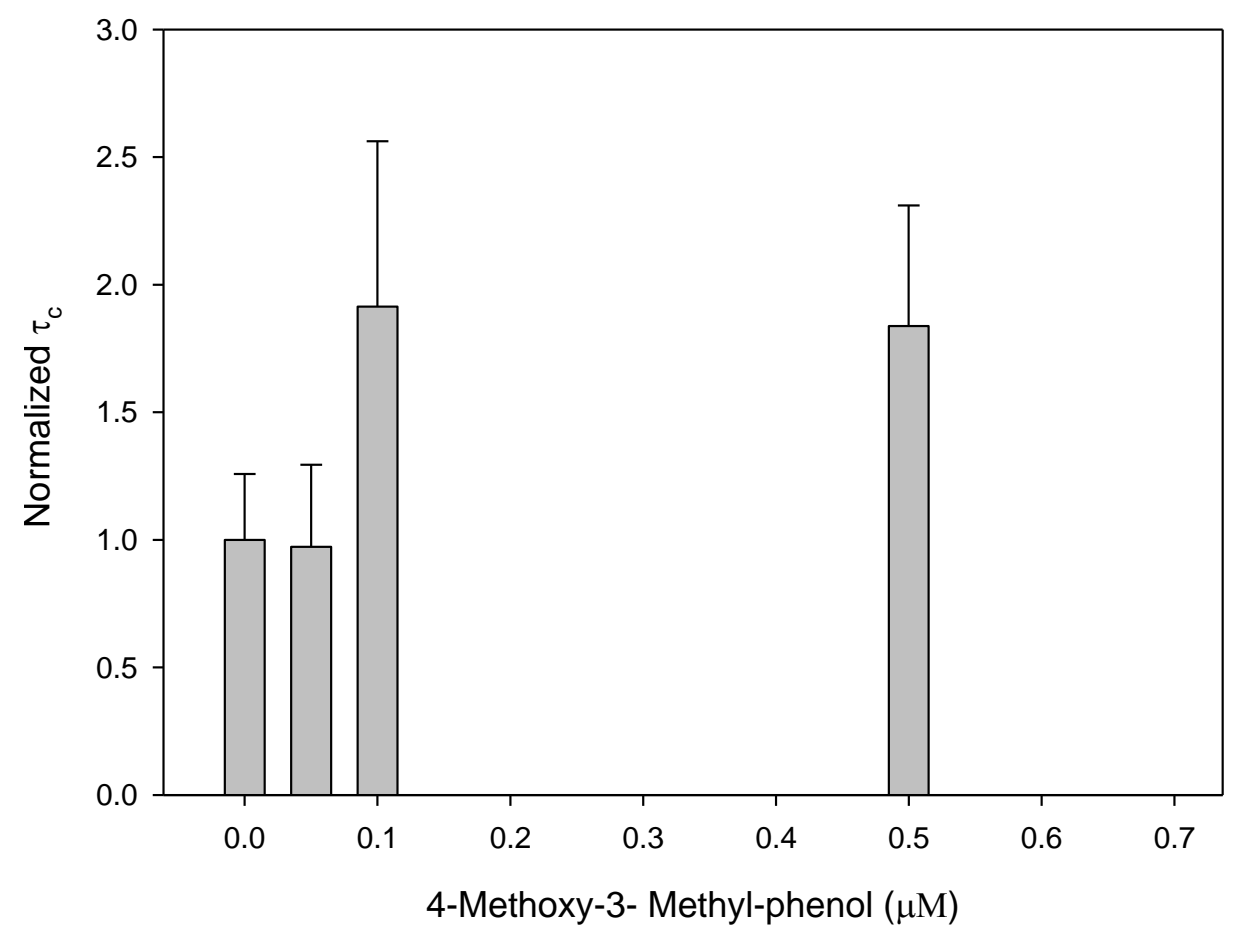

Fig 3.13 4-Methoxy-3-Methyl-phenol has no significant effect on channel closed time $\left(\tau_{\mathrm{c}}\right)$

Normalized average closed time vs. concentration of 4-MmC. Absolute value for average closed time for control is $1.5 \pm 0.4 \mathrm{~ms}$. Each points represents the average of at least four measurements \pm standard error. 


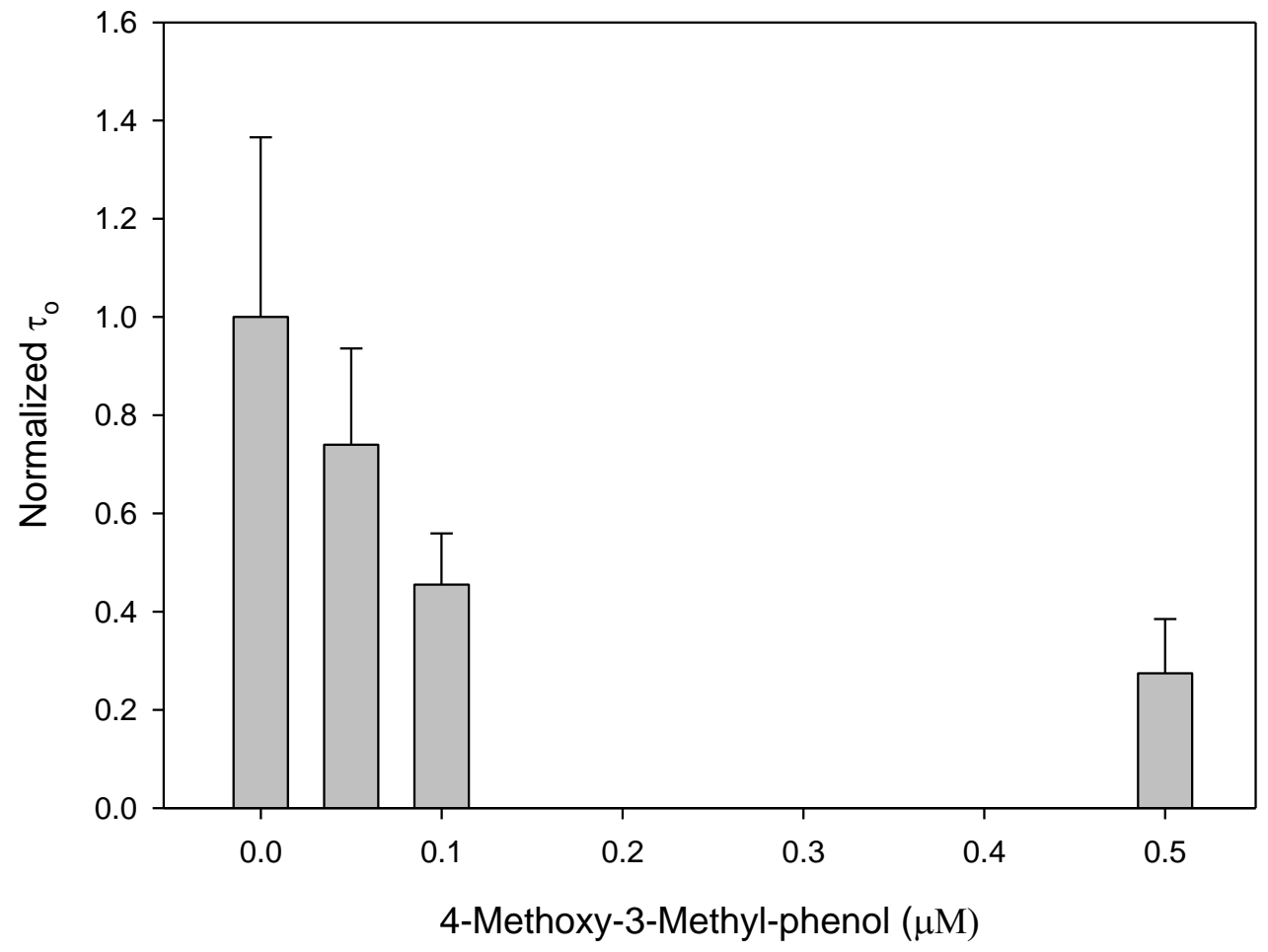

Fig 3.14 4-Methoxy-3-Methyl phenol decreases channel open times $\left(\tau_{0}\right)$.

Normalized average closed time vs. concentration of 4-MmC. Absolute value for average open time for control is $2.1 \pm 0.8 \mathrm{~ms}$. Each points represents the average of at least four measurements \pm standard error. 


\section{CHAPTER IV}

\section{DISCUSSION}

In this study, two new potent RyR inhibitors were synthesized which are derivatives of known RyR modulators, 4-chloro-3-methyl phenol (4-CmC) and $\mathrm{K} 201$. 4-CmC is a effective activator of both RyR1 and RyR2 at sub millimolar concentration [43] . By replacing the chloro in the 4 position with a methoxy group, we have converted an electron acceptor into an electron donor and converted a channel activator into a potent channel inhibitor (Section2.4.2). In a similar manner, synthesizing the dioxole derivative of K201 converts a RyR inhibitor into a more potent electron donor and significantly increases its effectiveness as a channel inhibitor. This nontraditional approach toward drug design was motivated by our earlier observations that all RyR activators tested were electron acceptors, while channel inhibitors were electron donors. Moreover, there is a correlation between the effectiveness of these drugs and their potency as either electron donors (inhibitors) or acceptors (activators) [12].

K201 is a strong electron donor which inhibits both the skeletal [44] and cardiac muscle RyR [45, 46]. It has been shown to have both antiarrhythmic and cardioprotective properties. These beneficial effects on the heart appear to be caused by its ability to decrease the diastolic calcium leak mediated by the cardiac ryanodine receptor. Much effort has been directed toward understanding how K201 functionally modifies RyR2, but the basic mechanism of its action still remains unclear. 
Some research groups propose that K201 stabilizes the RyR by causing the reassociation of the FKBP12/RyR1 complex in skeletal muscle and the FKBP12.6/RyR2 complex in cardiac muscle [47]. This interpretation has been challenged by the observation that K201 almost completely inhibits the $\mathrm{Ca}^{2+}$ leak from normal dog heart SR under conditions in which the FKBP12.6 has completely dissociated from RyR2 [48]. Our previous observation has also shown that K201 suppressed the channel activity from normal and FKBP12 depleted RyR1 with similar potency. Moreover, RyR1 does not reassociate with FKBP12 in the presence of $20 \mu \mathrm{M} \mathrm{K} 201$ - a concentration that significantly inhibits single channel activity [39].

Our single channel experiments have shown that the inhibitory effect of K201 is four times more potent in suppressing the cardiac calcium release channel activity than skeletal muscle channel activity. The $\mathrm{IC}_{50}$ for inhibiting the $\mathrm{RyR} 2$ is $1.13 \mu \mathrm{M} \pm 0.68 \mu \mathrm{M}$ compared with $3.98 \mu \mathrm{M} \pm 0.79 \mu \mathrm{M}$ for RyR1. The difference in inhibitory potency might be caused by structural differences between RyR1 and RyR2, which leads to a different number of available drug binding sites. Alternatively, it is also possible that the binding affinity of K201 to RyR2 is larger than the binding affinity to RyR1or that RyR2 accepts electrons from K201 more readily than RyR1 does.

Previous publications have shown that $\mathrm{K} 201$ is not specific for the SR $\mathrm{Ca}^{2+}$ release channel. It has been reported that K201 nonspecifically inhibited transmembrane $\mathrm{Na}^{+}$, $\mathrm{Ca}^{2+}$, and $\mathrm{K}^{+}$currents [49] and that the cardioprotective effects of the drug were abolished when hearts were pretreated with inhibitors of protein kinase C [50]. K201 can 
also alter the gating of the dihydropyridine receptor [45] and has a natriuretic effect on the glomerular filtration rate [51]. Due to these multiple side effects, it is unlikely to be developed as a pharmaceutical product.

The 1,3 dioxole derivative of K201 is obtained by selective modification of K201 [46], resulted in a compound with enhanced electron donor properties. As expected, the dioxole derivative is a more potent electron donor, as well as a stronger channel inhibitor than K201. It suppresses both RyR1 and RyR2 activity at sub micromolar concentrations. We also have observed that the inhibitory effect of the dioxole derivative of K201 at the single channel level is reversible. Changing solutions following addition of the dioxole derivative restores the channel activity. This observation can be explained by the hypothesis in our previous publication that non thiol electron acceptors or donors interact with the ryanodine receptor by forming a reversible charge transfer complex.

A similar approach was used to develop a new drug targeting the RyR with enhanced electron donor properties by modifying the channel activator 4-CmC. 4-MmC is the most effective inhibitor among the three drugs examined in this study. The $\mathrm{IC}_{50}$ for $4-\mathrm{MmC}$ in inhibiting RyR2 activity is $0.14 \mu \mathrm{M} \pm 0.04 \mu \mathrm{M}$. Unlike $\mathrm{K} 201$ and the dioxole derivative of $\mathrm{K} 201$, the inhibition effect of $4-\mathrm{MmC}$ on RyR2 were only observed at lower salt concentration than has previous been examined ( $250 \mathrm{mM} \mathrm{CsMeSO}$ ), while channels were activated at higher salt concentration $(400 \mathrm{mM} \mathrm{CsMeSO}$ ). It appears that 4MmC's ability to inhibit RyR2 involves an electrostatic interaction. We are not certain why 4-MmC activates RyR2 at high salt concentrations but inhibits channel activity at 
lower salt concentration. The salt concentration inside of most cells is around $160 \mathrm{mM}$. At this low salt concentration, SR vesicles do not fuse to the artificial bilayers. As a compromise between reproducing physiological conditions and the necessity of the SR to fuse to the bilayer (high salt conditions), we examined channel activity at a salt concentration of $250 \mathrm{mM}$. Under these conditions, 4-MmC inhibits RyR2.

It has recently been shown that the two RyR2 inhibitors, tetracaine and flecainide differ in their mode of action. While tetracaine inhibits channel activity by increasing channel closed time, flecainide decreases channel open time, but has little or no effect on the average closed time of RyR2 [42, 52]. Authors of these studies postulate that the beneficial action of flecainide stem from its peculiar ability to block RyR2 channels only when the channel is in the open state [42]. In section 3.4, we show that the three drugs tested in this study, in a manner similar to flecainide, show no significant effect on the closed time of RyR2 at concentrations at or less than their $\mathrm{IC}_{50}$. The drugs we have tested appear to inhibit open RyR2 channels by reducing the RyR2 open channel mean burst duration.

Moreover, consistent with our results at the single channel level, three drugs showed significant anti-arrythmogenic effect when they were tested at the whole heart level and the whole animal level. Addition of $1.0 \mu \mathrm{M}$ of the dioxole derivative of K201 suppressed EADs and restored the normal AP profile in an adult female rabbit heart. 4-MmC and K201 were tested on FKBP12.6+/- mice for ventricular tachycardia. The data revealed ventricular arrhythmias in $60 \%$ of the FKBP12.6+/- mice. However, treatment with 4- 
MmC (a significantly more potent anti-arrhythmic compound) completely eliminated ventricular tachycardia. These studies were done by our collaborators Dr. G. Salama at the University of Pittsburgh and Dr Xander Wehrens at Baylor College of Medicine.

Although these drugs inhibit single channel activity and the $\mathrm{Ca}^{2+}$ leak associated with $\mathrm{HF}$ and ventricular arrhythmias, they don't affect the normal action potential, nor do they inhibit normal excitation contraction coupling. It is still unclear why these drugs only affect defective channels. It is possible most of the binding sites for these drugs are in the mouth of RyR, which is accessible when the channel opens. A leaky channel opens for a longer period of time while the normal channel opens and closes relatively quickly. When the channel opens for a longer period of time, the drug has enough time to bind and inhibit channel activity by decreasing the open time of the channel. Normal channels, presumably don't open for a long enough period of time for drug binding to the corresponding sites. Alternatively, during normal EC coupling there may be steric considerations that hinder the binding of these drugs.

Although the drugs described in this study show beneficial effects in stabilizing the calcium release channel of both skeletal and cardiac muscle SR at the single channel level, they exhibited no effect on measurements of high affinity ryanodine binding. Unlike most channel inhibitors, we have demonstrated that these drugs close down both RyR1 and RyR2, yet they don't inhibit high affinity ryanodine binding. It appears as if these are two conformationally closed states of the RyR, one which results in inhibition of ryanodine binding and one which has no effect on ryanodine binding. 
We have previously observed a good correlation between a drug's ability to act as an electron donor, and its ability to close down channel activity [12]. These new drugs that we have developed inhibit channel activity at submicromolar concentrations. At these low concentrations, our assay for measuring electron donor properties loses its sensitivity. This assay has to be improved in order to effectively compare electron donor properties of new more potent drugs.

Future work related to this project should be focused on two directions. In this study, the inhibitory potency of $\mathrm{K} 201$, the dioxole of $\mathrm{K} 201$ and 4-MmC were compared. 4-MmC inhibited RyR2 channel activity at lower salt concentration (250 mM CsMeSO 4 ), while the other two drugs inhibited channel activity at high salt concentrations $(400 \mathrm{mM}$ $\mathrm{CsMeSO}_{4}$ ). It would be more persuasive if we could compare the inhibitory effects of these three drugs under the same experimental conditions. More single channel experiments should be done to test the K201 and its dioxole derivative at low salt concentrations. In order to further test our hypothesis that it's potency as an RyR inhibitor, and to determine if more potent electron donors are more effective inhibitors of arrhythmogenic activity, more new drugs need to be synthesized and tested at the single channel level, at the whole heart level and at the whole animal level. Furthermore, if these new drugs inhibit channel activity by deceasing the channel open time, and they seem to single out "leaky $\mathrm{Ca}^{2+}$ channels" it would be interesting to see if these drugs fail to inhibit channel activity if the $\mathrm{Mg}^{2+}$ concentration is increased to approximately $1 \mathrm{mM}$ concentration. Increasing the $\mathrm{Mg}^{2+}$ concentration to a more physiological range is known to decrease the channel open time and result in more rapid flickering of the channel. If 
under these conditions these drugs fail to inhibit single channel activity, this offers an explanation of why these drugs do not alter normal E-C coupling in normal cardiac preparations. 


\section{REFERENCES:}

1. Choong-Chin Liew, V.J.D., Molecular genetics and genomics of heart failure. Nature Reviews Genetics 2004. 5: p. 811-825.

2. Xander H. T. Wehrens, S.E.L., Steven Reiken, Roel van der Nagel, Raymond Morales, Jie Sun, Zhenzhuang Chen, Shi-Xiang Deng, Leon J. de Windt, Donald W. Landry, and Andrew R. Marks, Enhancing calstabin binding to ryanodine receptors improves cardiac and skeletal muscle function in heart failure. 2005. 102(27): p. 9607-9612.

3. van Oort, R.J., et al, Ryanodine receptor phosphorylation by calcium/calmodulindependent protein kinase II promotes life-threatening ventricular arrhythmias in mice with heart failure. circulation, 2010. 122(25): p. 2669-79.

4. Lynda M. Blayney, F.A.L., Ryanodine receptor-mediated arrhythmias and sudden cardiac death. Pharmacology \& Therapeurics, Aug 2009. 123(2): p. 151-177.

5. Sperelakis, N., Physiology and Pathophysiology of the heart. 3rd ed. 1995: Kluwer academic publishers.

6. Warwick R, W.P., Gray's anatomy. 35th ed: British.

7. Joachim Krebs, M.M., Calcium: A Matter of Life or Death. 1 ed. 2007: Elsevier. 
8. Zheng Liu, J.Z., Pin Li, S. R. Wayne Chen, and Terence Wagenknech, Threedimensional Reconstruction of the Recombinant Type 2 Ryanodine Receptor and Localization of Its Divergent Region 1*. THE JOURNAL OF BIOLOGICAL CHEMISTRY, 2002. 277: p. 46712-46719.

9. Ashcroft, F.M., Ion Channels and Disease channelopathies. 2000: Academic press.

10. Brandt, N.R., A.H. Caswell, S.R. Wen, and J.A. Talvenheimo, Molecular interactions of the junctional foot protein and dihydropyridine receptor in skeletal muscle triads. J. Membr. Biol, 1990. 113: p. 237-251.

11. Jones, L.R., L. Zhang, K. Sanborn, A.O. Jorgensen, and J. Kelley, Purification, primary structure, and immunological characterization of the 26-kDa calsequestrin binding protein (junctin) from cardiac junctional sarcoplasmic reticulum. J. Biol. Chem, 1995. 270: p. 30787-30796.

12. Benjamin S. Marinov, R.O.Olojo., Ruohong Xia, Jonathan J. Abramson, NonThiol Reagents Regulate Ryanodine Receptor Function by Redox Interactions that Modify Reactive Thiols. Antioxidants \& Redox Signaling, March 2007. 9(5): p. 609-621.

13. Ruiwu Wang, L.Z., Jeff Bolstad, Ni Diao, Cindy Brown, Luc Ruest, William Welch, Alan J. Williams, and S. R. Wayne Chen, Residue Gln4863 within a Predicted Transmembrane Sequence of the Ca2+ Release Channel (Ryanodine 
Receptor) Is Critical for Ryanodine Interaction. J Biol. chem, 2003. 278(51): p. $51557-51565$.

14. M Scoote, P.A.P.-W., A J Williams, The therapeutic potential of new insights into myocardial excitation-contraction coupling. Heart, 2003. 89(4): p. 371-376.

15. Rudy, Y.; Available from: http://rudylab.wustl.edu/overview/index.htm.

16. Dincer, U.D., Cardiac ryanodine receptor in metabolic syndrome: is JTV519 (K201) future therapy? Diabetes Metab Syndr Obes, 2012 5: p. 89-99.

17. Kubalova Z, T.D., Viatchenko-Karpinski S, Nishijima Y, Györke I, Terentyeva R, da Cuñha DN, Sridhar A, Feldman DS, Hamlin RL, Carnes CA, Györke S, Abnormal intrastore calcium signaling in chronic heart failure. Proc Natl Acad Sci, 2005. 102(39).

18. Marx SO, R.S., Hisamatsu Y, Gaburjakova M, Gaburjakova J, Yang YM, Rosemblit N, Marks AR., Phosphorylation-dependent regulation of ryanodine receptors: a novel role for leucine/isoleucine zippers. J Cell Biol, 2001. 1534: p. 699-708.

19. Reiken, S., et al., beta-adrenergic receptor blockers restore cardiac calcium release channel (ryanodine receptor) structure and function in heart failure. Circulation, 2001. 104(23): p. 2843-8. 
20. Reiken, S., et al., Beta-blockers restore calcium release channel function and improve cardiac muscle performance in human heart failure. Circulation, 2003. 107(19): p. 2459-66.

21. Braunwald, E. and M.R. Bristow, Congestive heart failure: fifty years of progress. Circulation, 2000. 102(20 Suppl 4): p. IV14-23.

22. Bristow, M.R., et al., Cardiac-resynchronization therapy with or without an implantable defibrillator in advanced chronic heart failure. N Engl J Med, 2004. 350(21): p. 2140-50.

23. Oda T, Y.M., Yamamoto T, Tokuhisa T, Okuda S, Doi M, Ohkusa T, Ikeda Y, Kobayashi S, Ikemoto N, Matsuzaki M, Defective regulation of interdomain interactions within the ryanodine receptor plays a key role in the pathogenesis of heart failure. Circulation, 2005. 112(17).

24. Trimm, J.L., G. Salama, and J.J. Abramson, Sulfhydryl oxidation induces rapid calcium release from sarcoplasmic reticulum vesicles. J Biol Chem, 1986. 261(34): p. 16092-8.

25. Zable, A.C., T.G. Favero, and J.J. Abramson, Glutathione modulates ryanodine receptor from skeletal muscle sarcoplasmic reticulum. Evidence for redox regulation of the $\mathrm{Ca} 2+$ release mechanism. J Biol Chem, 1997. 272(11): p. 706977. 
26. Kalckar, H.M., Differential spectrophotometry of purine compounds by means of specific enzymes. J. Bio.Chem, 1947. 167: p. 461-475.

27. Mueller, P., Rudin, D. O., Tien, H. T. \& Westcott, W. C., Reconstitution of cell membrane structure in vitro and its transformation into an excitable system. Nature 1962. 194: p. 979-981.

28. S.M.Sine, F.J.S.a., Data transformations for improved display and fitting of single-channel dwell time histograms. Biophysical Journal, 1987. 52(6): p. 10471054.

29. Laver, D., The Power of Single Channel Recording and Analysis: Its Application to Ryanodine Receptors in Lipid Bilayers. Clinical and Experimental Pharmacology and Physiology 2001(28): p. 675-686.

30. BJERRE, D., Metalloproteins Couple to the Calicium Release Channel in Sarcoplasmic Reticulum, in Physics. 2006, Portland State Univ. p. 54.

31. McDonald, J.H., Handbook of Biological Statistics. 2nd ed. 2009: sparky house publishing.

32. Ibrahim A. Salem *, M.S.E.-M., Kinetics and mechanism of color removal of methylene blue with hydrogen peroxide catalyzed by some supported alumina surfaces. Chemosphere, 2000. 41: p. 1173-1180.

33. N. Kaneko, O.T., T. Sakai and H. Oota, 1,4-Benzothiazepine derivatives. 1995. 
34. M. Yano, S.O., T. Oda, T. Tokuhisa, H. Tateishi, M. Mochizuki, T. Noma, M. Doi, S. Kobayashi, T. Yamamoto, Y. Ikeda, T. Ohkusa, N. Ikemoto and M. Matsuzaki, Correction of defective interdomain interaction within ryanodine receptor by antioxidant is a new therapeutic strategy against heart failure. Circulation, 2005(112): p. 3633-3643.

35. Kiriyama K, K.T., Arita M, Effects of JTV-519, a novel anti-ischaemic drug, on the delayed rectifier $\mathrm{K}+$ current in guinea-pig ventricular myocytes Naunynschmiwdeberg's Archives of Pharmacology, 2000. 361(6): p. 646-653.

36. Hasumi H, M.R., Shimamoto K, Hata Y, Kaneko N., K201, a multi-channel blocker, inhibits clofilium-induced torsades de pointes and attenuates an increase in repolarization. Eur J Pharmacol, 2007. 555(1): p. 54-60.

37. Donald J. Hunt, P.P.J., 1 Ruiwu Wang, Wenqian Chen, Jeff Bolstad, Keyun Chen, Yakhin Shimoni, and S. R. Wayne Chen2, K201 (JTV519) suppresses spontaneous $\mathrm{Ca} 2+$ release and $[3 \mathrm{H}]$ ryanodine binding to RyR2 irrespective of FKBP12.6 association. Biochem J, 2007 June 15. 404(Pt 3): p. 431-438.

38. L. H. Sternbach, H.L., E. Reeder, T. Hayes and N. Steiger, A new type of 1,4benzothiazepine derivative. Journal of Organic Chemistry, 1965. 30: p. 28122818.

39. Yanping Ye, D.Y., Laura J. Owen, Jorge O. Escobedo, Jialu Wang, Jeffrey D. Singer, Robert M. Strongin and Jonathan J. Abramson, Designing Calcium 
Release Channel Inhibitors with Enhanced Electron Donor Properties: Stabilizing the Closed State of Ryanodine Receptor Type 1. Molecular Pharmacology, 2012. 81: p. 53-62.

40. Higgins, L., et al, An assessment of the reaction energetics for cytochrome P450mediated reactions. Arch Biochem Biophys, 2001. 385(1): p. 220-30.

41. Al-Mousa, F. and F. Michelangeli, Commonly used ryanodine receptor activator, 4-chloro-m-cresol (4CmC), is also an inhibitor of SERCA Ca2+ pumps. Pharmacol Rep, 2009. 61(5): p. 838-42.

42. Hilliard, F.A., et al., Flecainide inhibits arrhythmogenic $\mathrm{Ca} 2+$ waves by open state block of ryanodine receptor $\mathrm{Ca} 2+$ release channels and reduction of $\mathrm{Ca} 2+$ spark mass. J Mol Cell Cardiol, 2010. 48(2): p. 293-301.

43. Herrmann-Frank, A., M. Richter, and F. Lehmann-Horn, 4-Chloro-m-cresol: a specific tool to distinguish between malignant hyperthermia-susceptible and normal muscle. Biochem Pharmacol, 1996. 52(1): p. 149-55.

44. Almassy, J., et al., Effects of K-201 on the calcium pump and calcium release channel of rat skeletal muscle. Pflugers Arch, 2008. 457(1): p. 171-83.

45. Kohno, M., et al., A new cardioprotective agent, JTV519, improves defective channel gating of ryanodine receptor in heart failure. Am J Physiol Heart Circ Physiol, 2003. 284(3): p. H1035-42. 
46. Wehrens, X.H., et al., Protection from cardiac arrhythmia through ryanodine receptor-stabilizing protein calstabin2. Science, 2004. 304(5668): p. 292-6.

47. S. O. Marx, S.R., Y. Hisamatsu, T. Jayaraman, D. Burkhoff, N. Rosemblit and A. R. Marks, PKA phosphorylation dissociates FKBP12.6 from the calcium release channel (ryanodine receptor): defective regulation in failing hearts. cell, 2000. 101: p. 365-376.

48. Yano M, K.S., Kohno M, Doi M, Tokuhisa T, Okuda S, Suetsugu M, Hisaoka T, Obayashi M, Ohkusa T, Kohno M, Matsuzaki M., FKBP12.6-mediated stabilization of calcium-release channel (ryanodine receptor) as a novel therapeutic strategy against heart failure. 2003. 107(3): p. 378-80.

49. Kimura, J., et al., Effects of a novel cardioprotective drug, JTV-519, on membrane currents of guinea pig ventricular myocytes. Jpn J Pharmacol, 1999. 79(3): p. 275-81.

50. Inagaki, K., et al., Anti-ischemic effect of a novel cardioprotective agent, JTV519, is mediated through specific activation of delta-isoform of protein kinase $\mathrm{C}$ in rat ventricular myocardium. Circulation, 2000. 101(7): p. 797-804.

51. Lisy, O. and J.C. Burnett, Jr., New cardioprotective agent K201 is natriuretic and glomerular filtration rate enhancing. Circulation, 2006. 113(2): p. 246-51. 
52. Watanabe, H., et al., Flecainide prevents catecholaminergic polymorphic ventricular tachycardia in mice and humans. Nat Med, 2009. 15(4): p. 380-3. 